\title{
Endangered Humanities at a Time of Crisis in the EU and Beyond: Shrinking, Downsize and The Itinerant Academic
}

\author{
Eleftheria Pappa
}

\begin{abstract}
I am still convinced that our transmitting the message of ancient arts and civilisations to our age is of fundamental importance. To fulfil this task could not be easy in our civilisation in which the humanities are pushed into the margins but just therefore the role of out subject is indispensable for understanding our roots, identity and task. Moreover, I wish you pleasant adventure in the discovery of the unknown and never give up!
\end{abstract}

- Jan Bouzek, June 2015

\section{Going Public at a Time of Crisis?}

Swift changes to the organizational structure, funding and teaching of the humanities in many countries across the EU, as well as of the cultural heritage sector, have resulted in many speaking of the future of the humanities as "endangered." In particular, fields such as history, archaeology, anthropology, classics and modern languages have received some of the stronger blows. The present article deals with the challenges and outlook of a subset of the humanities (mainly archaeology, ancient history and anthropology) and the cultural heritage sector in the European Union (EU). It examines EU and national policies on academic research and heritage management, including the impact on its practitioners. Its aim is to delineate the current state of affairs, highlight efforts at the professional group, national and international levels so as to address some of the existing problems and suggest new avenues for tackling these issues. In a nutshell, it addresses the crux of the issue: why invest in something as "shaky" as the humanities dealing with the past, at a time of precarious present and future?

The ongoing economic crisis that has severely affected Europe has had a detrimental effect on the humanities and on the heritage management sector. Different approaches by national governments coalesce on the point of the curtailing and downsizing measures employed, albeit in different ways. These policies, despite glossy and highpitched rhetoric as to the contrary, work in tandem with a broader tendency to undervalue and demote the role of the humanities in contemporary European societies, mediated via national and supra-national authorities. This tendency, however, goes hand-in-hand with the market-oriented and "technocratic" ethics of the neoliberal economic model that has permeated Europe, where the open, democratic political debate is being increasingly replaced by unchallenged, top-down decision-making by unelected agents of supra-national institutional structures that pursue specific sets of economic goals. These goals recurrently and consistently fail to address existing, large-scale social problems, while setting the precedent of substantial democratic deficiency. The severe repercussions of these developments have reached a visible zenith during the past five years. As such, the demotion of the humanities in Europe is symptomatic of a general crisis of values in Europe that is manifested in a wide array of social and political phenomena.

By and large, the challenges that humanities face are multifaceted and complex, with impact on the academic disciplines, the cultural heritage sector and the lives of their practitioners. How are we poised to address these 
challenges with the state and super-state apparatuses and with the public in such rapidly-changing socio-political circumstances? What will the outlook be over the next twenty years? What is the future of academics? The difficulties that the academy faces have been explored in breadth in the past few years. In a recent volume (Killebrew and Scham 2015) the difficulties faced by archaeologists, in particular, are explored in detail, offering advice, through personal life narratives, on how to carve meaningful professional paths outside academia. The perspective hinges mainly on the impact of the neoliberal policies and realities on the individual. Almost two decades ago, a different type of article by McGuire and Walker (1999) addressed the same problems from the lens of how professional groups should respond to the wider institutional framework of the academy and the cultural heritage sector. My goal here is different from both these approaches. I will frame the analysis in terms of how the function of institutions requires reform, but also in terms of the individual's necessary contribution as a member of a collectivity, underlining group responsibility and action as solutions to issues that can be dealt with institutionally through collective initiatives.

But why is this important in the first place? Why is it important to maintain funding for archaeology and ancient history departments, why indeed study archaeology or ancient history at all even in the wealthiest countries of the EU, since chances are, graduates will end up scrambling for a living? Why not fund departments that will provide these people with the means to address the needs of a technologically forward, economically salient 21st century world? Framing the debate, I will respond to these questions after sketching out the backdrop of the neoliberal policies on research and education that characterize EU and national agendas, and which reflect the functional underpinnings of the EU. I will show how they privilege the "interests of the market" to the detriment of quality of research, public good, and social vision. First, I analyze the structure and effects of the EU and national policies on academic research and heritage management in the EU so as to examine the policy responses to the EU economic crisis vis-à-vis mainly archaeology and the cultural heritage sectors, using case studies. I will address the measures taken to counterbalance the economic crisis as this affects humanities, the impact of these measures, the challenges and responses that they pose.

The discussion will be integrated in a critical analysis of the EU structure and function, which has shaped policy that disfigures research, both directly via EU policy, and indirectly, through the latter's influence. This will be followed by an in-depth analysis of what constitutes a "EU at a time of crisis," using specific examples. This part is indispensable to understanding EU and national policy on research in the humanities during this time. This is not only because EU policy affects directly research in the continent. Essentially, the financialization of research and its obsession with metrics-based evaluation on the level of EU policy transcends legal documents and borders, and crystallizes in social mentalities of what is of value within the individual member states, independently of official EU policy. Thus, subsequently it is perpetuated in an authoritative, top-down and unchallengeable value system, independently of the supra-national policies that gave rise to it, through the grip of the neoliberal market forces on national policy bodies and university management.

Additionally, the market-oriented EU areas of competence indirectly impinge on the function and value of the humanities vis-à-vis the public. Discourses on their inherent value are gradually being replaced by ideas on how to promote a cultural product intended for public consumption, thus taking a narrow view of their function and creating a deterministic frame of perceiving the value of the humanities. This ideological determinism permeates policy but also finds a new life in the ideological preoccupations it perpetuates and reproduces through the training and employment of new generations of academics and heritage practitioners - often done unconsciously of the biases in which the educational-academic system has been embedded.

Two case studies will be used. Since different EU member states are governed by different legislation, characterized by widely different traditions in educational approach and heritage management policies, case studies will be country-based, rather than theme-based according to sector. This will facilitate a holistic understanding of the way the economic crisis was approached in each case, and the measures and responses to it, as the underlying historical and social realities in different countries vary widely. The alternative way of adopting a sector-based examination that would lump examples from across countries in each case (research funding, heritage management) endangers a superficial analysis that glosses over major, country specific differences of historical dimensions, thus distorting the understanding of the processes involved. So as to offer a representative sample of the variety of challenges and responses, the two case studies selected are countries at the opposite ends on the economic ranking within the EU, and whose approaches to the study and value of the humanities regarding the ancient past are radically different: The Netherlands and Greece. For example, the Netherlands' different approaches to heritage management, as well as to the funding and teaching of archaeology, present a different pattern of challenges and responses than in Greece, where the state apparatus plays a predominant role in both academic humanities and the cultural heritage sector. One 
point of convergence appears to be the deployment of an array of similar measures of "counter-acting" the crisis, which result in the demotion of the value of these disciplines, albeit orchestrated in different ways.

\section{The Functionalist Europe: Technocracy, the Reduction of the Political and the Democratic Gloss}

The ongoing economic crisis aggravated previously existing difficulties, inadequacies and weaknesses on several levels. These are the outcome of weaknesses in EU legislation relating to policies concerning the allocation of research funding and the paths that new research is expected to take, as well as to particular national priorities with regard to these issues. Effectively, while speaking of the current "state of the humanities" across the EU is valid in as much as a basic central EU policy framework, with funding tools, exists for the allocation of research funding, along with EU-wide heritage management policy guidelines, deep-rooted structural differences at national level create a disparate mosaic of problems and outlook across different EU member states.

So as to understand such policies, and the responses to them, one needs to understand how the EU envisions itself, its structure, goals and actions. Increasingly, the European dream, as a union of socially democratic countries, appears withered, with many perceiving it a chimera of an optimistic period of economic growth. The rhetoric of leaderships across the continent has followed an increasingly nationalistic and self-referential tone in the past halfdecade, permeating media and social opinion, which yet lacked meaningful substance on the role of the EU and its future. While this may have been startling for people raised with the European dream as an attained ideal, these developments pivot on the very conditions and structures of the establishment of the EU. The Treaties of Paris (1951; "European Community of Coal and Steel”) and Rome (1957; "European Economic Union") were concerned with the creation of a tax-free zone for trade in the commodities of large industries (steel and coal), unencumbered from transaction costs. This "common market" goal, progressively expanded, and with it, the concept of the common market was substituted by that of the "single market." With the Maastricht Treaty (1991), the expansion of the goals and range of actions envisaged by the Union did not entail a modification of the essentially functionalist underpinnings of its formation, i.e. as an economic-industrialist group brandishing the banner of geopolitical stability, even as it morphed into the European Union (e.g. Bartl 2015: 33).

The problems, therefore, are rooted in the origins and structure of the EU since its conception. Several studies emphasize that the substantive democratic deficit in EU governance is the direct outcome of the functionalist underpinnings of the EU. Bartl (2015) demonstrates two main reasons for this: 1. the narrow range of topics open to democratic debate with the EU and 2. the depoliticization of EU goals and policymaking, leading to increasingly shallower debates, which replace genuine political debate on politically salient matters, substituting them with discussions on "procedural" matters about how the a priori goals would be best implemented. Thus, concerns such as social impact, health, environment etc. remain outside consideration, because the expansion of the "market" silently privileges all other concerns.

The principle of subsidiarity, aiming at weakening this democratic deficit, was introduced with the Treaty of Lisbon, but its implementation has so far led to a further strengthening of the democratic deficit (Bartl 2015), as was predicted early on by its critics, some of whom favored the principle of 'proportionality' instead (Davies 2006). Since the principle of subsidiarity is often used to expand EU competencies on social matters (i.e. matters beyond the framed competencies of the EU), it results in aggravating the democratic deficit by entering the parameter of "market" into policy-making on socially salient and others matters, where the "interests of the market" should not be of relevance or at least not of primary interest (Bartl 2015). Seen under this light, the substantial democratic deficit and lack of interest in things "non-economic" in EU governance, as well as the commonplace, transnational criticism that the EU places center-stage the economic benefit of oligarchies at the expense of majorities, is not a source of surprise.

The above observations, common in the legal discourse, however, shadow the causes behind this approach of privileging the market-related competencies over other concerns — as if the EU legislative-executive power nexus were impersonal or as if describing a natural ecosystem where things "just are" by nature. Rather than symbiosis, the EU nexus of power increasingly recalls more interrelationships akin to parasitism. In reality, the bias behind the goal setting of the EU promotes specific interests, national, corporate or those of lobby groups, which is clearly seen in an additional parameter of governance, the unaccountability of emerging power structures. These parameters will be 
discussed below, as they affect directly the new climate of decision-making in Europe and the resultant disfiguring of "ideals" in EU discourse, central to research and public education.

\section{Economic Crisis and the "Neutrality of Expertise"}

The EU economic crisis took the cue from the 2008 USA collapse of mortgage bonds, showcasing several of the widely acknowledged contributing factors (lapsed ethics, standards and accountability of financial institutions, failures in risk management in corporate and national governance). What was never officially stressed to the European public was that a monetary union that was not based on a financial union would present many problems and inequalities even without an imported economic crisis. Ironically, however, the process of monetary "harmonization" caused divergence within the EU, bringing to the fore latent centrifugal forces. European Central Bank (ECB) policies were structured in a way that favored strong economies, such as Germany, from the outset. A monetary union based on a strong currency, with the Deutsches Mark $(\mathrm{DM})$ as its predecessor, could not but work detrimentally to the economically weaker countries, whose economies relied on a cheaper currency that boosted exports and supported growth, one also which-importantly - they could regulate. A union that was only monetary and not fiscal was prone to falter very soon - as it did. In addition, the artificial imposition of a debt ceiling at 3\% of public budget for its member states further aggravated the situation (Douzinas 2013), especially since Germany continues to break EU law by keeping its surplus higher than the allowed limit while demanding observance of the debt ceiling from others. The simple truth that within the monetary union of the EU one country's surplus is another's deficit appears to have escaped many. The resulting EU à deux vitesses functioned as a catalyst for a dynamic of further erosion within the $\mathrm{EU}$, as a deepening economic crisis was easy to precipitate under these conditions.1

The main response to the crisis was to set up ad hoc mechanisms (ESM, ESFS, temporary liquidity mechanisms from the ECB and "loans" by the EU/IMF) disguised under the mantle of financial control and fiscal discipline. These were ill thought out, and had one main target: to nationalize private loss and privatize national profit. Budgetary policies on national level repeatedly were portrayed on the ranks of the EU as having to appease private credit-rating companies in the USA, which often betted against national economies - in essence rendering private bodies situated across the Atlantic as stakeholders in national policy-making of sovereign countries in Europe. 2 The measures taken were allegedly "technocratic," aiming at the amelioration of the economy through neutral, expert knowledge. Throughout the crisis, however, several world-known economists contradicted the wisdom of austerity meted out for the southern European countries by the EU elite. The rationale was that lowering budgetary expenses would lower debt. In reality, the contractionary, extremely recessionary measures (severe lowering of wages, pensions, accompanied by unprecedented and irrational tax hikes) led to increased unemployment, mass closure of business, mass individual and business migration, a situation that led to a downward spiral of the economy. The measures, instead, benefited the lenders (e.g. Germany) whose cheap supply of money through the ECB was lent at much higher interest rates to the countries to "be rescued" - a phrase that perpetually continues to remain in EU official debate, and remarkably, it is not used euphemistically.

The bias of the functionalist goal-setting as shown in the responses to the crisis consists in labeling strategic decisions on politically salient matter "technocratic," i.e. allegedly apolitical decisions, leaving open questions as to what constitutes good governance within the EU. Masquerading measures taken with strategic interests in mind as neutral and expert, thus "technocratic," leads to axiomatic assumptions about the nature of policy a country needs to follow, and stops all dialogue at its tracks. While the rationale behind the measures is not allowed to be discussed, "heeding the agreements" has become an EU mantra, whose rationale is never put to discussion even though they obviously do not work: not in the case of Portugal, Cyprus, Spain, Greece or Ireland. This practice was responsible for the collapse of dialogue between the EU and a newly elected Greek government of January 2015, which led to a national referendum and subsequent elections in July and September of the same year respectively.3

Greece is a case in point, and will be used below to demonstrate the absurdity of the policies followed, if the ostensible, proclaimed reasoning behind them is taken at face value. The imposed measures have led the country to an unprecedented socioeconomic collapse, and have failed and continue to fail with no end in sight, 4 even in the admission of the IMF. The organization, however, despite its own belated selfcriticism 5 continues to administer the same measures that have already proved a patent failure. Further such austerity packages continue to be even against agreed terms, six years on. While the amelioration of the Greek economy cannot be the real aim, asset 
stripping on the pretext of fiscal deficit and the recapitalization of Franco-German banks, which had predatorily invested in Greek state bonds over a number of decades from the 1990s, due to them yielding higher interests than in domestic financial institutions (Varoufakis 2014) may come closer to the real agenda.6 The response of the EU to the worsening situation that could endanger Franco-German banks was a nationalization of private debt and privatization of national profit: thus through three so-called "Memoranda of Understanding" (MoU) (also known as "loan agreements" and "rescue packages"), the debt of French and German banks was turned into public debt, which affected mostly Greek tax payers, even as it was distributed across EU countries. In essence, the bonds issued by the Greek state and held by foreign financial institutions (predominantly German and French banks) amounted to a 'debt' that was distributed across EU nation-states as national debt through the famous PSI mechanism. Effectively, this EU plan forced European nations to pay for the recapitalization of German and French banks and other financial institutions that had made unwise investments over a number of years. The costs of these measures taxed (literally) mainly the Greeks, who were subjected to onerous loan agreements simply to maintain payments to the lenders and so as to keep servicing an ever-increasing debt.7 This is because the so-called rescue packages consist in a mechanism of "servicing an ever-increasing debt," which means they are used to refinance various western European banks, as imposed austerity further worsens the economy and thus increases the debt (e.g. Varoufakis 2014) As the EU-prescribed austerity continues, which has none of the allegedly expected results, this process is perpetuated ad infinitum because the austerity program creates more debt, and thus more avenues for creating profit for the lenders. Tellingly, while Germany has pressed for crippling austerity in Greece so as to stave off the crisis, it chose a different path for itself, fiscal stimulus, which led to quick economic recovery (Karanikolos et al. 2013: 1324). The crippling austerity imposed on Greece followed other failures of the EU, namely the attempt to curb cross-national inequality by focusing on the reduction of differences in macro-economic indicators, without taking into account the domestic (national) context (Papatheodorou and Pavlopoulos 2014).

In parallel, a system of appropriation of Greek public property was set up, so that national property could be "privatized" in crisis-induced prices. This consists in the EU structuring a new fund (TAIPED), essentially managed by the EU, in which the public assets of Greece are collected (state infrastructure, coastlines, groups of airports, energy companies) and then expropriated at a tiny fraction of their true value, with the money allegedly contributing to the reduction of an ever-increasing, through the austerity policies, unsustainable debt. The public assets themselves come into the hands of often foreign, private consortia, established in the countries that demand the austerity policies that aggravate the Greek economy. This creates an obvious vicious circle for Greece but an incentive for the creation of austerity policies for its "lenders", especially since money lending (for the so-called aid packages) occurs at much higher rates than ECB lending in the lender-countries (which receive cheap money from the ECB and then lend it at high interests to those countries in need of "rescue"). For example, the privatization of several peripheral Greek airports (19 in number), serving small border island communities and being therefore necessary as a lifeline for these communities, was taken over by the German Fraport company, as part of this process. A main stakeholder in this company is the German federal state of Hesse (Kouvelakis 2016: 67). Effectively, the asset stripping on the pretext of budgetary deficit undermines the very process of recovery by seizing the very means the country owns to reverse the economic onslaught (Pavlopoulos 2015).

Construing thus "national interest" in a narrow way, without recourse as to whether social justice is part of it, the EU continues to implement policies that are detrimental to national entities and to the Union as a whole. The other face of the failure to address the economic crisis was the damaging, for the Union, portrayal of the crisis. Instead of communicating economic realities in a balanced way, a concerted media campaign of intently demonizing specific nations though the press by creating an ethnically-tainted narrative of profligate-lazy southern Europeans was promoted, so as to cover the EU's own structural asymmetries and the realities behind the debt. Masterminded so as to soften public opinion in the rest of Europe for the aggressive austerity policies to be inflicted on the countries to "be rescued," it sought scapegoats not in the extant regulations or practices of the Eurozone, on the predatory investments of financial institutions or the corruption of interconnected EU "elites" (the well-documented collusion of private and public interests) but in national entities, and the very people that constitute them, at that. The countries that were involved in the "loan agreement" programs came to be known as PIIGS (Portugal, Ireland, Italy, Greece, Spain - by chance?). Even academics, including historians were not innocent in the mediatic, ethnic demonization frenzy.8 The orchestrated, vituperative narratives were channeled through a wide array of public speeches on the part of EU officials and national leaders, reinforced by the media, reviving ethnic-based stereotypes reminiscent of the inter-war period. For most people, such lowly "discourses" formed part of a shameful period of European history, forever buried in a different era. Yet nationalistic stereotyping and clichés became the norm from mid-2010 
onwards, which through repetition transcended their overt propagandistic character and dominated the mainstream political debate but also daily public life. They became factoids, "truths" that run routinely in daily life, unchallenged by logic. The hegemonic role of media was reinforced by uneven linguistic distribution that boosted real power asymmetries: while several dozen millions across the EU speak or understand to some degree French, German, and English, languages of lesser numbers of speakers (Portuguese, Greek) put an obstacle to a balanced flow of information as to what really was taking place. "The avalanche of ignorant commentary on Greece" (Douzinas 2013: 7) invited measured responses that were yet unable to turn the tide of misinformation and prejudice (e.g. Karyotis and Gerodimos 2013; Pappa 2013).

The neologism debtocracy emerged precisely so as to indicate new forms of colonization through, on the one hand, the induced "impoverishment-ization" policies and the recurring EU ultimata threatening weak national economies with bankruptcy (via the control of the ECB banking system across the EU), and on the other, through the strong manipulation of public opinion via the mass media. In reality, these practices reflect new forms of colonialism that take their cue straight from the 19th and 20th centuries (Hamilakis 2013).

\section{| Only the Market Matters! Contravening the EU's Own Laws}

In several cases both national and EU legislation is flouted by the austerity dispensed by the EU.9 Several of the contractionary measures, for example, led to such breadth and depth of socio-economic collapse that the effects on the national populations, even biologically, were not taken into account, as EU law dictates. As a rare, critical study observes: "The Directorate-General for Health and Consumer Protection of the European Commission, despite its legal obligation to assess the health effects of EU policies, has not assessed the effects of the troika's drive for austerity, and has instead limited EU commentary to advice about how health ministries can cut their budgets (Karanikolos et al. 2013: 1330). The effects on public health across Greece, Portugal and Ireland were tremendous, yet "public health experts have remained largely silent during this crisis" (Karanikolos et al. 2013). In southern Europe alone, suicide rate markedly increased. In Greece, a country with until then one of the lowest suicide rates in the EU "a 40\% rise in suicides between January and May, 2011 [was documented], compared with the same period in 2010 (albeit from a low initial rate);" major depressive episodes, and a general deterioration of public health sketch the main outlines of the dismal picture (Karanikolos et al. 2013: 1328).

This is explained by the fact that in several EU official speeches, over a number of years since the onslaught of the crisis, the rights and needs of the markets were construed as a de facto priority over social needs, social justice and democratic rule. The direct contravention of democratic laws and regulations of both national and EU level was implemented by direct intervention in national policies via ad hoc, informal (unlegislated for) formations, such as the so-called "eurogroup" (a panel of EU finance ministers) which appeared suddenly and without any legal basis in EU or national legislation. This non-accountable (to anyone) power structure has assumed, nevertheless, the powers of an instrument of both legislative and executive power for politically salient matters involving different member states, while stupendously, at the same time, its procedures, goal-setting, and regulation enforcement cannot be challenged at the EU court of justice or anywhere else, since they are non-institutional and informal, as very cynically it was made clear by the EU Commission in July 2015.10 Essentially, set outside of an EU legal framework, that is, beyond the grip of the law, the eurogroup made decisions and forced their implementation at national level in Greece, regardless of the opposition they met from a democratically elected government, regardless of the fact that the procedures remained secret and regardless of the fact that the rationale behind the aims was not discussed, as the infamous saga of negotiations on the so-called Greek debt that took dozens of eurogroup meetings demonstrates.11

Such ways of "responding" to the crisis contravene basic notion of democratic governance within the EU, as financial control bodies (that came to be known as "Troika") were formed by so-called economic experts chosen by the ECB, the EU and the IMF, unelected by anyone and not even accountable to the EU parliament. They startlingly came to replace national parliaments in shaping national policy. In practice, certain states came to be governed in large part via emails sent from abroad, amounting to the eyes of the citizen body as a parody of democratic process. Hijacking parliamentary institutions, often overtly, they assumed a less than shadowy dictatorial function that de facto annuls democratic legislation, presenting the austerity-inducing measures, privileging sectarian interests, as neutral, common-sense administrative measures.

Greece is a case in point. The country is currently under an officially unacknowledged, peculiar form of 
"protectorate" governance.

\begin{abstract}
There is a new austerity package, with further cuts and taxes-to an economy that has already lost a quarter of its GDP. The Greek government has lost any real legislative power, since any bill has to be approved by the Quartet [EU Commission/ European Stability Mechanism/ECB/IMF] before being submitted to the Parliament. On the side of the executive power, the tax-collecting body, the General Secretariat of Public Revenue, is now fully 'independent' of the elected government and is in reality controlled by appointees of Brussels. Decrees issued by the Secretariat have an equal value to decisions of the Cabinet-this is written in the Memorandum. Then there's the Council for Fiscal Discipline, with five members, functioning along the same lines. They are unaccountable to any governmental authority, closely monitored by the Quartet and can impose cuts on any expenditure if they suspect there might be a deviation from fiscal targets, which demand a 3.5 per cent surplus from 2018. Deprived of its levers, the Greek state is also being stripped of its remaining assets. (Kouvelakis 2016: 66-67)
\end{abstract}

How did it come to this? The Greek austerity is administered through the three MoU, which were (nominally) voted in the Greek parliament, albeit after intense and protracted political pressure from abroad leading to political instability and constant elections. The voting of the first two MoU flouted the stipulations of the Greek constitution and particular legislation on passing law bills (e.g. annulling the preview time that MPs are allowed, and the preview stage of parliamentary deliberations, where laws are debated before being passed in subsequent parliamentary sessions, as happened with the 2nd MoU in February 2012). Effectively, this resulted in the MPs being called to vote on "loan agreements" that ran over several hundreds of pages of technical documents and which were given to them only the night or two before - evidently without anyone being able to read the highly legal and technical text in full.12 The undesired loan agreements, in reality, a straightjacket, led to the voting in power of a socialist government in January 2015, which was consistently undermined by its EU partners, leading to new elections seven months later and a referendum in the summer of the same year.

The third MoU was signed by a new government (Syriza/Anel coalition) that was forced to ignore the outcome of the national referendum that had taken place a few days before and while the EU had forced Greek banks to shut down for an indefinite period of time by stopping the emergency funding mechanism that is regulated by the European Central Bank. This move was aimed as a bargaining chip on the efforts of the EU elite to increase the pressure on the Greek government to accept further austerity (and recession) despite the worsening - on all fronts - situation in the country. This pressure mechanism was unprecedented in the history of the EU and disregards any notion of democracy and good governance. Despite the pressure generated by the closure of banks and strict capital controls, the outcome of the referendum was a resounding "no" against the austerity meted out by the EU elites, albeit one that was completely ignored given the prevailing asymmetries of power between a bankrupted member state and an EU with full powers over the banking and economic system of said member state.13 Punitive measures were in large part intended as setting an example to other states (Portugal, Spain) that would potentially look to Greece for alternative ways of addressing the economic crisis, beyond the anti-social EU doctrines.

The Troika-EU leadership, dominated (uninstitutionally) by Germany, forced the country already from the beginning of the crisis to completely abolish collective labor agreements - an achievement of the struggles for labors rights over the course of the 20th century - and privatize on a mass scale, ostensibly so as to service an unsustainable debt, partly created through the structural asymmetries of the Eurozone itself. The privatization program is run through the TAIPED fund, mentioned above. It is telling that in order for this fund to run from mid-2012 onwards, the law regarding the parliamentary majorities for approving bills had to urgently change on June 9, 2012 since the government had failed in a special committee in the parliament that took place the same day to achieve the necessary majority and pass it legally. Thus retroactively, on the same day, the Greek law was modified in order to accommodate the undemocratic and illegal procedures that were affecting the appropriation of public infrastructure.14 The list in the privatization program includes even profitable and healthy public companies. Such extreme measures continue to be demanded, even if their implementation in other EU states has patently failed, leading to re-nationalization. Among them, imminent is the privatization of the "public good" water corporation of Greece. Such privatizations of water companies have a history of failure in the very same countries that continue to demand them from Greece. Tellingly water companies in Germany became public in the 1990s, after the failures of privatization to maintain the quality of drinking water for public safety standards led to renationalization (Varoufakis 2014).

Thus, these measures consist in transferring the burden of responsibility and the weight of 'punishment' for the crisis completely only to one party (and a nation, at that), rather than to both sides (i.e. also financial institutions in Germany and France that invested in Greece). They do so by contravening laws, as well as at the expense of basic 
humanitarian considerations, and civil rights attained over a 130-year long struggle (i.e. collective labors agreements). This is clearly unethical by various yardsticks and on many fronts, embodies a solipsistic notion of economic prosperity and absolves of responsibility the agents behind the asymmetrical power relations within the EU. Instead, the mentality of imposing the MoU on Greece and other countries annuls the main tenet behind the notion of the "investment:" that the probability of profit pivots on the possibility of loss. Instead, the MoU assure profit to the investors of Greece (i.e. banks) as well as ascertaining that any potential losses would not be incurred by them, but by EU taxpayers and Greece. Thus, stupendously they shift all the burden of investment losses to (nominally) the EU tax-payers (which receive it back through loan repayments), but mostly to Greek citizens (who are not recompensed by anyone). Thus through EU measures, the investors (financial institutions) faced no possibility of loss and had their gains guaranteed by rolling the debt onto EU taxpayers. This forms clearly a EU construction that perverts the notions of social democracy that the EU supposedly espouses. Economy being subject to politics, politics being subject to personal interest, prejudice and not rarely, arrogance, the institutional response to the crisis has teamed with errors, biases on ethnic stereotypes and "technocratic" approaches that do a disservice to the EU and its nations, socially and economically. The increasing amount of the break of ethics and lack of accountability in current EU governance amount to an enduring lack of morality in EU action, which is characterized by social injustice, punitive measures and national demonization and victimization, treating economically weak nations as if they were social pariahs that "need a lesson" on one hand, and on the other, as bankrupt companies that can be dispensed with.

\section{EU Economic "Crisis," the Market and the Humanities}

The EU already has announced drastic plans to cut funding for the humanities, as it is evident in the new plans concerning the Horizon 2020 Program, the EU Framework Program for Research and Innovation, despite the constant, official rhetoric on supporting excellence in research. A planned $35 \%$ cut to the budget relegated to the humanities was announced in October 2014 by the then EU commissioner-designate for Research, Science, Innovation (C. Moedas), presaging a deterioration of the status of the humanities in the continent.15

The Horizon 2020 program forms the main tool for research funding in the EU. The intentional shrinking of the importance that humanities appear to attain within these new plans compounds already existing problems of EU funding allocation, i.e. the low funds relegated to the research projects in the humanities, the professional uncertainty that the award of short grants (1-3 years) generates for non-tenured academics, the international mobility as a necessary precondition for obtaining them and the slim chance of remaining employed once the period of 2-3 years of post-doctoral research has been completed. Often early career research grants (in the previous ERC scheme, on the rung of $€ 800,000)$ are reserved for a tiny and ever-shrinking minority of researchers. The ensuing "bottleneck" effect translates into a significant loss of human capital and public investment, as the majority of those specialists compelled to leave academia have been educated at public expense (Saltini-Semerari 2014). It also leads inadvertently to an erratic development of research fields, whereby previously-funded sub-fields can silently disappear completely from a country, not out of a conscious, premeditated decision by some competent public committee but due to chance factors from one year to the next in the assessment of grant proposals.16

These problems compound existing inadequacies stemming from the EU framework on tertiary education. Controversial educational policies aimed at harmonizing university curricula across the EU, although they remain inadequately implemented, have begotten their own monstrosities. The Bologna Process, for example, launched in 1999, was an effort by European authorities, universities and other stakeholders to create some form of tertiary education pattern as a blueprint of standardization across the continent. The intended harmonization of Higher Education in the non-binding Bologna Process was politically enshrined in the 2007 EU Lisbon Treaty. Its premise hinged on assumptions about quality, 17 whose political underpinnings became clearer in the Lisbon Treaty (Capano and Piattoni 2011). In reality, the proposed tertiary degree system is based on the shorter, neoliberal (i.e. marketoriented) British model (BA, BSc etc.), with little recourse to the multitude of longer, more labor-intensive firstdegree courses across other EU states. Its real premise was to transform universities into economic actors, which would boost the competiveness of the European universities and would render quality "quantifiable" (Bal et al. 2015, 53). Early in that process, optimistic studies concluded that increasing globalization would function as a stimulus for competition in Higher Education and force state intervention as a guarantor of high quality (Kivinen and Nurmi 2003). This optimism is difficult to maintain nowadays. 
Extra-EU initiatives have also followed a similar trajectory. Archaeology, in particular, has not been aided by the Council of Europe 2007 Malta Treaty, which transforms cultural heritage management into a purely administrative procedure, in contact more with spatial planners, than with the arts and culture sector.18

\section{Funding the Humanities or Feeding the Irrational?}

Attracting external funding has become the main task of a researcher, at the detriment of the quality of his/her work output. Frequently the efforts yield no gain in grant acquisition but result in mass losses for the universities. The EU and national prescriptions of incessant grant competitions, the constant pressure to gain grants on the basis of "excellence" and "competitiveness" have actually plagued research. If tenured, the university expects a number of grants per year from staff, often setting a benchmark (Blommaert 2015); if not, then obtaining a grant, in the humanities, is often the only way of remaining employed. This is an integral aspect of the increasing neoliberal model that has encroached and "occupied" university management, education and research in Europe (Lorenz 2015; Papari 2015; Bal et al. 2014; Engelen et al. 2014; Halffman 2014).

The absurdity is well illustrated by the application process entailed in research grants. The application process is assumed by a member of staff but often supported by teams of university staff tasked specifically with consultations on the drafting of grant proposals, thus increasing the potential for success. Thus, in the effort of attracting money, the university spends financial resources when the success rate can be as low as 2\% (Blommaert 2015). In some cases, the extra-academic input on supporting grant proposals reaches the degree of lobbying at the appropriate EU contact points in the respective countries. This already enters a significant bias in the system, privileging the betterfunded universities, which happen to be those in the wealthier EU countries and have stronger lobbying connections (e.g. with the industry).

This external set of bias in the preparation of grant proposals is added to the inherently problematic assessment procedures endorsed by EU, and national funding bodies. The assessment is based on metrics and quantifications with little rational substance as markers of quality on the level of individual. One of them is the journal impact factor. Journal impact factors are used widely as proxies for individual research quality, in which they are misleading. The impact factor arose to denote the average number of citations to articles published in that journal in the two preceding years, which statistically is a dubious measure for assessing journal quality, much less individual article quality; yet now it has been promoted, through misuse, to a proxy for individual researcher quality, albeit without any statistical basis supporting that function (Gruber 2014, 170). Citation metrics such as the so-called h-index disadvantage early career researchers, as they take years to accumulate (Gruber 2014, 174-175; Burrows 2012). Additionally, citation metrics per se cannot reliably be used as a measure of quality. Factors such the author's personal position, professional networks, attempt to please colleagues etc. can increase the citation of an article; alternatively, research can be cited due to the faults or inadequacies contained therein (Gruber 2014,171-172). This all shows that statistical counts per se are statistically worthless and meaningless in assessing quality of research.

These citation metrics become completely irrational when applied to the humanities, which use extensively print-only media for publications. Anglo-American corporations such as Google and the Times Higher Education were given the ability to "determine their own criteria of evaluation" for data ranking, for which "humanities hardly matter" (Lorenz 2015, 9). The monograph, the main output in the humanities, does not feature in these rankings. Since a great percentage of the publication output of these disciplines is in print-only journals and books, the digitalonly citation counts provide worthless statistical data. Another factor distorting the value of citation counts is the size of the research field. An article in a popular field such as Olmec anthropology will attract a much higher readership and conceivably more citations than a smaller field, such as Iron Age Alpine archaeology. The linguistic bias offers another factor that renders the ranking regime an absurdity. Additionally, citation counts serve mainly mono-glottal research "markets" or at most, publications in the widely spoken languages. One could not hope to accumulate many citations writing in their (mother) tongue of Hungarian, Finnish, Greek, or Czech, even if extensive publications in the humanities are produced in European languages spoken by few million people. Yet that (low count) is not a measure of the quality of research per se. Such rankings are then unreliable in assessing one's quality of research in the humanities, yet they determine grant assessment process worth billions of euros. What is instead needed is a qualitative review of one's work, not abstract metrics that are conceptually and pragmatically unreliable as measures of quality.

An additional factor plaguing the assessment process of EU-based research grants is the lack of competence/ expertise of the respective panel/committee members in the subject areas they are called to assess, as well as their often inadequate usage of extant regulation to compensate for these inadequacies. For example, panel members of 
the "Human Past" in the ERC Starting Grant funding scheme, a main EU funding scheme until recently, were often inadequately versed in the broad gamut of subjects they were called to assess. The synthesis of the committees did not account for unconscious linguistic, cultural and national biases. Often the discrepancy is such that specialists in the history of 20th century history of market economics and others whose expertise ranges from medieval Frankish society to European post-war development are called to assess applications on the Neolithic in Europe, with no prescribed need to justify their assessment vis-à-vis the double peer-review of the proposals. The "redress" function that theoretically enables the applicant to respond to the assessment is merely a formality. The actual procedures followed during such proposal assessment remain a "black box" even to the consultants employed by the universities to aid the proposal preparation, or in Blommaert's (2015) word "carefully guarded secrets."

Thus, the hundreds of hours spent on each proposal submission, of several salaried individuals, per grant proposal, multiplied by the thousands of applications submitted annually amount to millions of hours spent on, effectively, no outcome. Millions of taxpayers' euros get lost, and ironically, in an effort to gain money on the part of the university as Blommaert (2015) succinctly notes. A success rate of $1.3 \%$ for the Horizon 2020 program, as remarked in the same study, is not a mark of quality, or else "all academics in Europe are bad ones." It is clear that this process for discerning excellence through competitiveness "will have cost more millions to the EU academic community" (Blommaert 2015) - with the resources spent not on generating research, but on pointless bureaucratic pursuits. "The system of selection is, when all has been said and done, simply irrational and unreasonable" (Blommaert 2015). These factors, inter alia, account for the fact that despite the university, i.e. public investments, in human and financial resources, several of the larger EU grants are often referred to in various circles as amounting to little more than a lottery.

What is not mentioned in Blommaert's well-argued but common-sense critique, approached from a different disciplinary field, is that in the humanities partaking in this process is not merely a way for an employed academic to attain tenure or for a team to gain more funding for extending the research - but the only way for an academic to become or remain employed.

An ERC or Marie Curie grant, for example, may be the only way for a young academic in the humanities to stay employed, as university chairs become rare and even teaching positions are often non-existent or offer a low number of teaching hours that are inadequate for covering even basic expenses. Yet, an ERC proposal runs on well over 30 pages of dense text (often over 16000 words), takes often months to prepare (either of unpaid hours or during salaried hours) and can enlist the help of several staff members, all paid through tax-payers. The applicant is expected to submit two forms, the first containing a mini-version of the proposal often running in ten pages. Unless the applicant progresses to the next stage, the "substance" of the proposal in the much longer second form $(\approx 10,000$ words), is never read by anyone - no peer reviewer, no assessment committee, no one outside the applicant and his/ her advisers - if there are any.

Experience with the system leads to stalwart disillusion. Buttressing this empirical data, one can also use the statistical evidence provided by the ERC funding scheme to document the (unconscious ?) bias of the system in the distribution of grant success rates. These are concentrated in the wealthier EU states, with the stronger lobby mechanisms, and in universities that can afford grant proposal consultants.19 An EU-commissioned monitoring report on the social sciences and humanities (SSH) projects "funded under the Societal Challenges and Industrial Leadership" acknowledged that the humanities and arts formed only 9\% of the funded projects (Hetel et al. 2015, 6). Another important finding was the statistical verification of what one would expect through even a dalliance with the EU funding system as an insider: there exists a wide geographical divide in the SSH contributors, as they come from the older and more established members of the EU (in descending order: Germany; the Netherlands; the United Kingdom; Spain; Italy; France and Belgium). "Together, the top seven countries account for $73 \%$ of the SSH coordinators while only 3\% of SSH coordinators come from the EU-13", i.e. the eastern European countries that joined the EU recently (Hetel et al. 2015, 6). While the authors note the "geographical divide" as a crucial finding, in reality they identify a divide that is at its core political and economic, underlining the asymmetrical power relations embedded in the EU, which are reproduced through its agencies. This comes into sharp contrast with the slick rhetoric of the purported aims of "harmonization" of EU-wide research or the continuously reiterated aspirations of "excellence."

The trends described compound the already dim view of assessing academic and scientific quality broadly, where an obsession and fixation with metrics seemingly has permeated a swathe of disciplines. "They [indicators] ignore and destroy the variety of knowledge forms and practices in various fields of study. That what is not measurable and comparable, does not count, is a waste of energy and should therefore be destroyed. In the indicator game, a 
book of four hundred pages published by Cambridge University Press hardly counts, or does not even count at all; a three-page article does. The specific publication system of (a part of) the natural and life sciences has been forced upon the rest of the sciences, even where it does not fit." (Halffman and Radder 2015, 167). Gruber (2014) contends "I do not know where this obsession with measuring, the urge to quantify everything comes from." That is not hard to comprehend. It is the direct outcome of the financialization of the European university through the neo-liberal reforms, which affect education and research, crystallized in EU and national policy. Lorenz (2015, 7-8) considers the corporate-dominated ranking regime of metrics and quantifications a "de-professionalization of the faculty," as the monitoring of the quality is not relegated to the professional body, but to managerial interests and political agendas "replacing professional ideas and practices concerning the judgment of quality - and thus of professional selection - by the 'metrification of output' in both the domain of teaching and of research." This obsession for quantification disadvantages mostly the humanities.

\section{| The Humanities and...Market Economics on the National Level}

This already problematic framework for allocating funding (lack of transparency in the allocation of EU funding, bureaucratic and counter-productive absurdities) discussed above, is further exacerbated by a mentality of intentionally decreasing the importance of the humanities at national level, reflected in the continuous cuts to national funding. Although there exist significant structural and ideological differences across different EU national settings, individual countries have followed the same trajectory of responding with cuts in education and research of the humanities, albeit of different magnitudes.

The neo-liberal model of university that has permeated since the 1980s even those European countries supposedly shielded from rampant market-based powers is based on a new type of management that is characterized by financialization, marketization and quantified performativity. It views market control as the medium for socioeconomic development, narrowly conceived (Bal et al. 2014; Lorenz 2012). Managerial controls, demands of quantifiable outputs in the form of audit with pre-set quantified goals, and efficiency "interpreted as at least the self-financing of organizations, and if possible [expectations of being] profitable" (Lorenz 2012, 605) form a radical break with the past. Institutional deficiencies derive from this business model, where dispensable staff and the institutional deficiencies generated by this model are masqueraded as "personal" lack of competence and failure. This forms a major, radical break with the past, a break from the vision of the university as a public good, open to all, sanctioned by a well-governing, democratic state.

British universities were the first to enter the neo-liberal model, whereas other countries, such as the Netherlands, are following closely. Across Europe, despite the established practices, the economic crisis has deepened the university-as-business model. Criticism has been slow to mount as the process was gradual and initially crept in silently through reformations of laws. A gradual realization of the changing circumstances caused fierce criticism, albeit the resistance from within is tempered by the precarious employment circumstances this system imposes on its staff.

The economic crisis has precipitated these developments. Austerity measures taken and the gravity of the cuts depend on economic robustness, national priorities, history of budgetary planning and public opinion. While the weaker players of the EU have opted for minimizing research funding almost in every sector, the prevailing ramping austerity mentality has not left even the economically much stronger northwestern EU members unaffected. Countries such as Greece and Portugal, which were placed under international economic supervision, effectively lost the ability to determine their own fiscal policy. For them, budget planning became the prerogative of the foreign "economists" of their respective Troikas. This is part of the reason behind the severity of the measures taken in these countries, since governance was relegated to unelected individuals whose concern was "number crunching" at all costs. In several of the wealthier countries of the EU, however, similar policies followed in the same austeritypraising mantra, responding needlessly from a fiscal perspective, with severe cuts, massive overhauls and a more "corporate-oriented" management.

Cases of "overnight" decisions to close down entire university departments, curtail museums of historical and national importance and research institutions complete the rather dismal picture of exigency in the unwarranted economically obliteration of culture capital. For example, the Swedish government announced in late 2014 that it would close down the Swedish Institutes at Athens, Rome and Istanbul. Following suit, the University of Copenhagen 
announced severe cuts across the humanities, with the intended closure of the Department of Classics (February 2016).

What should the response be to such a level of threat? Should there be a concerted attempt to highlight, from a professional body's point of view, potential disadvantages? These conditions have left a vacuum of response, especially among the academic world, which due to its members' frequent mobility across international borders is not well organized in terms of voicing opposition or preserving labor rights (in contrast with other professional bodies). In publications, blogs and books, Dutch academics are increasingly criticized for "being prepared to put up with almost anything,"20 although this changed in the course of 2014-2015. One may draw a sharp contrast with the months-long sit-ins, organized by student organizations at public Greek universities. But these differing developments should be seen within their context, i.e. the tradition of consensus decision-making in the case of the Netherlands and a robust economy and social welfare system that can still support unemployed academics, in contrast with the Greek context's high insecurity and lack of avenues for professional achievements, aggravated by the abolishment of collective labor agreements since the 2010 EU intervention in the country.

Responses have often been small-scaled and grassroots, through the petitions and publications.21 On few occasions, responses to crisis-instigated measures have been successful, however. Plans to shut down the Swedish Institute in Athens, a research institution devoted to the study and dissemination of research in classical antiquity, were temporarily halted thanks to an international campaign of protest, using online petitions and open letters by academics, organizations for classics and archaeology etc.

\section{| Case Study 1: The Kingdom of the Netherlands}

The Netherlands has a population of over 16 million people. It is one of the wealthier countries within the EU, although its trade-based economy is highly susceptible to any global economy oscillations. Despite its economic strength, its response to the crisis could be construed by many as "preemptive" with rapid and radical decisions to downsize, merge and close down state-funded entities. One of the differences in how this affected living standards compared to other countries is the existence of a robust welfare state that offers a safety net to those in society who find themselves in a vulnerable position, mitigating the adverse socio-economic effects of the radical austerity measures.

Attention has been recently brought to the increasing financialization of Dutch universities, institutions that are either public bodies or verenigingen, associations (i.e. often relying on a trust fund as well as receiving funds from the state). The financialization of the universities is increasingly turning them more into corporate-functioning entities that abstain from investing in research, instead simply trying to attract state/EU funding via individual researchers, while minimizing expenses for teaching and research. Such measures (cuts, layoffs, merging of faculties) are presented as the only way for the economic survival of the institutions involved, much like the overbearing austerity policies across the EU. Tight fiscal measures are commonly depicted by the managerial elite as a sina qua non.

There exist 13 Dutch universities in the Netherlands. Access to the universities is open to everyone who has finished secondary education (VWO). The emergence of the smaller Liberal Arts Colleges, as parts of the general universities, emphasizes teaching over research, but also offers more exclusive education: the tuition fees charged are considerably higher than those of the general universities and admission follows a strict application and interview procedure (Bal et al. 2014, 57).

With a change in legislation in the 1990s, the adoption of the neoliberal model of university management resulted in a top-down bureaucratic model of operation, with a strict hierarchical function, which delineated "competences" linked to "functional profiles" across a hierarchical structure (Lorenz 2015, 7). This model was advanced through the increasing financialization of the universities, where the reduction of public funding in combination with the expansion of student numbers led to a structural change towards a business-like managerial style. Ineluctably, this shift led involvement with dubious financial tactics, including the consumption of investment banking products and the speculation games they involve (Engelen et al. 2014).

The new managerial style advances the ideal of quantifiable academic output, privileging only sectors clearly linked to economic gain. Academic quality is reduced to a matter of metrics through management-organized audits. Thus, the quality of research is measured by people, systems and means not in the position to assess the quality of 
work output. Lorenz $(2015,7)$ describes this set of circumstances as the loss of the "professional autonomy of the faculty", i.e. the undermining of its professionalism. Tenured positions become fewer, whereas the casualization of staff is the new norm, creating a cascade of negative effects for staff, students and ultimately, public education. Teachers of anthropology at Liberal Arts Colleges in Amsterdam, for example, found that the new neo-liberal, individualistic model of success, privileging personal success over public advancement of knowledge and teaching, and quantitative data over qualitative data, came into contrast with the self-reflexive epistemic methods of anthropology, but also with the central tenet of anthropology itself, which places human empathy center-stage (Bal et al. 2014).

These negative developments derive directly from state policy on the value and use of research fields, a value measured as short-term, immediate and direct financial output. Investment in research is then directly connected with the interests of the industry, through a state-sanctioned, top-down approach. "In the Dutch case the representatives of nine economic 'top sectors' have been installed by the government to determine which researchers shall live or die in the future. The 'top sectors' are: 1. Horticulture and Basic Materials; 2. Agri \& Food; 3. Water; 4. Life Sciences \& Health; 5. Chemical Industry; 6. High Tech; 7. Energy; 8. Logistics, and 9. Creative Industry.” (Lorenz 2015, 10).

\section{Valorization as Financial Output: A Pragmatic Approach or the Drive to Extinction?}

Research funding has been almost exclusively relegated to the Netherlands Organization for Scientific Research (NWO), the main body for funding research and science, supported by the Royal Netherlands Academy of Arts and Sciences. While the actual funding amounts have not been dramatically altered in recent years, new clauses and conditions that have been introduced for the preparatory stages of grant proposals significantly change the fields to which these fund are channeled. The new requirements in grant applications have been engineered to disadvantage those working in fields where no immediate economic output can be demonstrated, i.e. especially fields such as anthropology, ancient history, classics, and archaeology. The tangible, short-term economic gains expected by the state explain the recent entry of the "valorization" clause in the research grant applications, which determines which fields stay or become extinct in the Netherlands. Yet, the humanities have already suffered from lower budgets than those ascribed to other fields. This new clause is meant to measure the knowledge valorization of the research to be funded, expressed as the societal impact seen in a tangible form within 5 years, i.e. something that can be measurable or immediately demonstrable.

Specifically, this added pre-condition of "knowledge valorization" for a successful research project proposal requires from the researcher candidate not only to design and produce research that will yield some form of specified social impact - and within five years from the completion of research at that - but also to specify and organize the way this societal impact will be achieved. This clause of knowledge valorization has persisted despite initial criticism from those working in the humanities in the Netherlands. Effectively, the award of project grants impinges on the drafting of projects that include stages of research, and also some form of implementing or applying the research results. Thus, this precondition turns on its head the established practice according to which the valorization of research results (in history, archaeology, anthropology, classics etc.) is a task for those working in education policy and heritage management. Additionally, the expectation that the researcher assumes a role for which he/she has not received any relevant education or training, and which is the expertise of other professionals (i.e. the application/ implementation of results, especially in the humanities) seems to come against professional ethics, encroaching on other fields, which also face high unemployment.

The valorization clause introduces a new way of perceiving the benefits of knowledge, taking a particularly narrow view of the social benefit incurred by an epistemic field. In doing so, it encourages a market approach to scientific research, with results counting as some crypto-substitute for a market price tag on the research project. This cannot but lead to the stifling of academic research. By circumscribing the value of research in such a bounded way, policy prevents academic freedom from carrying out fundamental research, and from planting seeds for the future. The expectation of tangible, measurable results within the narrow time frame of five years minimizes the temporal frame in which scientific value can be appropriated to a negligible time slot. Yet, the history of science consistently shows that some of the greater human achievements are built on the accumulation of human knowledge, painstakingly gathered with no immediate economic output in mind. Some of the most innovative discoveries and advances were based on much older findings. The 20th century leaps in astrophysics would not have been feasible without 17 th century laws on gravity. Humanity had to wait for several centuries for tangible valorization, far more than the Dutch expectation of 5 years, as it has been pointed out by critics of this policy.

Thereby, archaeologists applying for research funding in the Netherlands, for example, are increasingly attempting to circumnavigate this clause by proposing the organization of small museum exhibitions related to some aspect of 
their project. This may be viable if one conducts archaeological research connected to some aspect of the country's history, less so in the case of research done in other parts of the world where the infrastructure or legislation do not allow such pursuits and for which no equivalent or appropriate museum would exist to take over their organization. The process of successfully applying for a research grant awards has thus increasingly become more difficult for those working in the humanities. A classicist would be left to devise knowledge valorization projects, as an added part of a grant proposal, instead of focusing on the long-term effects of generating knowledge and its slow, trickledown effect on society through education. Claims of useful impact, through the generation of knowledge, and social progress through the understanding of past human societies, make no strong cases for award and are therefore outright rejected. The economic crisis has thus speeded up a process of "pragmatism" and expected benefit tied into some form of economic output that had already been under way by the 1990s, with the adoption of neoliberal mindsets in university management. At the same time, since universities cuts mean no new positions, such grants are often the only way for an academic to stay employed. In the best of cases, the $\mathrm{PhD}$ graduates would only in part be absorbed for a short postdoctoral career. A longer-term employment becomes impossible for the majority, leading to the disappearance of expertise. To a large extent, this mentality mirrors that of the EU funding schemes.

\section{Financialization and Protest in the Public Space}

Strict austerity measures, implemented in a country with a robust national economy, one of the strongest within the EU, were preemptive vis-à-vis the potentially deepening crisis, and counter-productive, since economic growth and prosperity cannot come from attacking the knowledge society has built over centuries on the human condition. More pertinently, in addition to the immediate impact on the state of the humanities in the country, the allegedly exigent measures create a disconcerting precedent.

Articles in the media and in academia from within the country timidly started to focus on the "financialization" of Dutch universities, and by the 2010s they expressly castigated the "take-over" of the universities by corporatestyle managements. Their charges aim at the cost-cutting (in the name of so-called "efficiency") in research and teaching, running Higher Education institutions as if they were companies aiming at profit maximization, at the expense of their actual raison d' être: the education of Dutch and other citizens and the maintenance and expansion of a society of knowledge. Already in 2009, Prof. Bert van der Spek, lecturer of ancient history at the VU University Amsterdam, an expert in cuneiform studies, was brusquely commenting that, should the VU continue to invest in flashy buildings and other dazzling infrastructure, instead of investing in research, then "wordt de VU een groot stadion waar matige voetballers spelen" ("the VU will become a large stadium where mediocre footballers play"). In 2012, news broke out that the "VU faced margin calls to the tune of $€ 44$ million on 'naked' interest rate swap contracts written out on future loans for planned real estate projects" (Engelen et al. 2014, 1072-1073). As it seemed, the corporate-style management had not actually led to efficiency. Or any measurable gains. Coupled with reduced public funding, these losses instigated austerity measures. The jeopardy of losing disciplines and jobs led to initiatives of inter-faculty or inter-university merging of departments and schools, types of restructuring that nevertheless necessitated the layoff of staff, regardless.

By the fall of 2014, unprecedented by contemporary Dutch standards mass sit-in protests were unrolling at the seat of the College van Bestuur (the management committee) of the other university of the Dutch capital, the University of Amsterdam. They went on for months, attracting the attention of international media. Organized by students and members of staff, they protested the mass closing-down, merging and downscaling of entire departments, affecting mainly the humanities. The University of Amsterdam had previously proceeded in severe cuts in the humanities, announcing the cut of entire teaching programs and the planned disappearance of degrees. The movement "Save the humanities at the University of Amsterdam," scathingly criticized the imposition of "ruthless cuts on the Humanities," starting a petition: "Teachers, staff and students unite against these destructive plans. Support the action committee Humanities Rally in its resistance!"22 Van der Spek's comment, mentioned above, stressing that funds exist for other types of investment (e.g. unnecessary infrastructure), amounted to a pillory precisely against this reality.

Geared towards the Dutch context, Halffman and Radder $(2014,175)$ describe the "occupation" of the university by "management, a regime obsessed with 'accountability' through measurement, increased competition, efficiency, 'excellence', and misconceived economic salvation." They call for a "a public university aimed at the common good - and at the careful deliberation of what comprises 'the common good", so as to "offer (world) citizens and their organizations our knowledge, even if they cannot afford it”" (Halffman and Radder 2014, 175-176). They list practical 
steps towards the strategic achievement of these goals, noting however that managements are impervious to these steps. Their manifesto is a call to arms, of academic sorts: exit (from academia), legal action, "muddling through and work-to-rule" (i.e. intentionally deceiving managerial controls and rankings), sabotage, collective refusal, trade union actions, mass demonstration, "contra indicators as counter-measures" (i.e. to the international corporate-produced rankings), strike, contra-occupation, parliamentary and political action (Halffman and Radder 2015, 180-185).

\section{Celebrating Cultural Heritage While Closing Down Museums}

The Netherlands Cultural Heritage Agency (Rijksdienst voor het Cultureel Erfgoed, RCE) is a state agency tasked with the management of moveable and immovable cultural heritage in the Netherlands, as well as with what it terms "mutual heritage," the aspects of Dutch heritage found internationally through the colonial, maritime history of the 16th-17th c. (e.g. in Suriname, Indonesia, as well as with foreign forms of heritage found in the Netherlands (e.g. English shipwrecks). Independent (private) archaeological companies do exist and operate under an institutional framework for the protection of the archaeological heritage, often operating in collaboration with universities. At the intersection of research and cultural heritage, the Centre for Global Heritage, at the University of Leiden aims to study and develop new ways of approaching cultural heritage studies, calling for its inherent relevance with "archaeology, the social sciences, the humanities the technical and natural sciences and the design disciplines." 23

Somewhat paradoxically though, forms of culture that are considered to bring in revenue to the country through tourism are touted, such as large museums that attract millions of tourists annually (Lütticken 2014). In other cases, where such revenue is deemed of lower economic potential, the response is drastic, on the reverse. In 2012, it was decided that the public library of the Tropenmuseum, the Royal Tropical Museum of the Netherlands, which offers a post-colonial perspective on the 17th-19th century past of the Netherlands, would close down. The library's collections were literally handed out to every interested member of the public that wished to obtain a book, while part of the collection was shipped to Egypt, to be housed in the new library of Alexandria.24 And yet the Tropenmuseum is of unique importance in the presentation of national history in the country as its narrative of historical events and situations offers the much-needed post-colonial perspective, counterbalancing the hegemonic discourse of the "Golden 17th Century" of Dutch maritime trade and colonization. It offers localized narratives from Indonesia and other former Dutch colonies, demonstrating the effects of the Dutch trading network on some of the indigenous communities. By contrast, the Rijksmuseum, the Royal Museum of History, where hardly anything of the colonized people's perspective can be glimpsed in its narrative, underwent an ambitious and costly program of renovation, aiming to further raise Amsterdam's culture potential by selectively portraying aspects of Dutch history. The library of the Tropenmuseum was stunningly distributed across residents of Amsterdam who could receive a free book, if so they wished, with the rest being shipped to the new library in Egypt - a loss of historical and anthropological knowledge capital for the Netherlands.25

The archaeological heritage of the country is managed through excavations by municipal or private archaeological companies. The latter have suffered though the crisis, due to the domino effects of a lack of construction. If building projects cease, archaeological teams are not called in. Mass lay-offs were probably irreversible. A solution to that would be to increase public funding, but also public awareness and interest to the value of archaeology, as a sector that can generate information for periods of history for which no other information exists or which change the perception of historical eras. Large-scale projects such as the excavations of the Limes (northern Roman borders) can be a first port-of-call for boosting interest in a local context, in a country where archaeology is still considered a bit "fringe" as an occupation. "Without public, no Malta" (Scheerhout 2007), as was remarked with reference to the implementation of the Valetta Treaty stipulations in the Netherlands.

\section{Case Study 2: The Hellenic Republic}

The Hellenic Republic is a presidential, parliamentary democracy and member of the EU since 1982. With a population of nearly 11 million (according to the last census of 2001), it is one of the smaller EU members. Prior to the rapid expansion of EU membership to incorporate former Soviet Union members or countries under the influence of former Soviet Union, it had one of the lowest GDP in the EU. This translated into longer working hours, lower salaries and pensions, a weaker welfare state for disadvantaged social groups and an over-stretched 
national health care system. Being already a "weaker link" susceptible to the economic and financial vicissitudes, the 2008 economic crisis found Greece exposed to a growth bubble (Mitsopolous and Pelagidis 2009), facilitated by the liberalization of markets, EU inflows and high-risk intra-EU investment strategies and EU subsidies for the cessation of domestic production spheres (e.g. in the primary economic sector). The onslaught brought already by the first UoM led to the complete abolishment of the collective labor agreements and the worsening of labor relations on all fronts (Ntanos 2011), with a precipitous fall on living standards, already low by western European standards (e.g. Douzinas 2013). At the same time, with resettlement and asylum policy recommendations on how the EU should act in response to the displacement of people fleeing ongoing conflict in the Middle East and seeking refuge in Europe (e.g. Fargues 2014; Fargues and Fandrich 2012/14) falling on the deaf ears of the democratically deficient EU leadership, Greece has been forced to carry out the lion's share of the burden of this humanitarian crisis (with over 1 million people arriving/passing through in the country within 2015 alone).

\section{Humanities and Higher Education: Neoliberalism from the Outside}

Education is considered a central pillar of modern Greek society, providing the basis for the development of "free and responsible citizens" as set out in the constitution.26 Thus education is considered a public good, free and open to all. Throughout all three educational tiers, the state provides free education for all residents in the country (whether citizens or not). In reality, the free education provided by public schools is complemented by a system of private tuition education ("shadow education") with high prevalence. This is meant to provide added value by providing systematic and intensive tuition throughout secondary and tertiary education. The motivation behind the emergence of this private shadow education is the increase of success in the university entrance exams, which are extremely competitive.

Greece has 22 public universities, 14 Higher Education Technological Institutes and several other specific interest Academies. Compulsory education lasts nine years. Tertiary education is optional and accessible only though the particularly competitive Pan-Hellenic competition. The Pan-Hellenic exams are a state-managed, centralized examination system which functions both as high school end exams and university entrance examination. The content of the exams is identical throughout the country. They are held at the same date and time, safeguarding unbiased and objective results as much as possible. The higher the scores attained, the more likely it is for the candidate to end up at the university and department on top of his/her list of choice.

Given that attendance at all public universities is free regardless of the university or the subject, the demand for university places is high. Thus competition in the exams serves as the regulating mechanism given the finite number of places for each degree at each university. This is in contrast to the situation in other EU countries. Some EU member states have a policy of open registration to all secondary education graduates (e.g. Netherlands, Italy), regulating increased demand for some degrees (e.g. medicine) through a lottery system (Netherlands). Other EU states relegate undergraduate admission to the individual university through an application/interview system. The level of tuition fees charged by each university for specific degrees also plays a decisive role in the degree/university to be chosen (e.g. Britain). In such neoliberal educational systems, market forces play a determining role in the type of university one chooses given differentiations in fee levels, but in Greece this is not the case (Gerasimou 2006). Academic merit (construed narrowly as success in the entry examination, but ignoring talent for extra-curricular pursuits) is the only criterion of determining admission to a particular university or department.

To preserve research freedom and shield universities from industry interests driving research, public universities are constrained in accepting private funding (e.g. for biomedical research), as is current common practice in other European states. As universities are publicly funded (in some cases supported also by charging tuition fees for postgraduate degrees), their situation is exacerbated during an economic crisis. The ideology of their function, however, has not changed towards increased marketization. Public funding for education forms $2 \%$ of the public budget, one of the lowest within the EU (Papari 2015). Since public budgets are effectively determined by committees and panels of (foreign) unelected individuals working for financial institutions (Troika), the Greek state has little leeway in addressing this, in a peculiar situation of fiscal captivity in its own legal and physical territory.

The teaching quality remains high (as attested indirectly by the high number of graduate students and academics from Greece at foreign institutions, in proportion to the Greek population). Yet the depreciation of the humanities and the social sciences comes from the low budgets that limit the appointment of new staff, and abolish university seats. Since an education in the humanities relies exclusively on the public sector, this poses a major problem for the continuation of Higher Education in the country,27 at least to the level on which it operates. The shrinking of university departments is a corollary to the underfunding of the universities. Academic libraries are shrinking and 
forced to merge with significant problems met across the entire spectrum of the function/activities of academic libraries, as a result of the economic crisis (Vazaiou and Kostagiolas 2013). Further, although in Greece education is considered a "normal good" and "necessary commodity", there has always been a demand for life-long learning in Higher Education, including shadow education. The demand for Higher Education is considered inflexible (i.e. independent of other factors), although a recent study showed that the possibility of paying for the amelioration of the provision of the educational "good" is negatively affected by the salary reductions and the financial insecurity (Solaki 2014).

Unlike the Netherlands, where the financialization is a top-down programmatic approach intertwined with the state planning, the depreciation of education in Greece comes from extra-national agents that deploy neo-liberal practices to public good entities through a fiscal asphyxiation across all fronts of the national budgets (healthcare, pension system, welfare, public infrastructure).

\section{Cultural Heritage, the De-secralization of National Imaginary and the Unraveling of the State}

The ancient past in modern Greece forms a powerful cache of resources from which to draw on so as to express authoritative power and high moral point in the present (Kotsonas 2012; Hamilakis 2012; Hamilakis and Yalouri 1996). As such, the organizational aspects of fields related to the ancient material culture in Greece are governed by a distinct set of mentalities regarding the fields' importance to the very existence of the state. Any cuts to services have a demonstrably different degree of significance in the eyes of the public than those in other European countries (Hamilakis 2012b; Hamilakis and Yalouri 1999; Karakasidou 1994). Given a long history of looting and transfer of antiquities to countries outside Greece, the state through its agencies is legally the sole entity tasked with heritage management.

The (mostly Greek) academic fixation with deconstruction found a fertile ground in the national imaginary of Greece and its antiquities. Plenty of efforts focused on deconstructing the superstructure of a discourse allegedly built in the nation-making of Greece in the 19th century, with the contribution of the European colonial powers, their political agendas and romantic philhellenism (e.g. Hamilakis 2012; Gourgouris 1996). These discourses emphasize the role of the archaeological record in the perception of a grandiose past (the Classical antiquity, but also early historical periods, such as the Minoan civilization), as symbolic resource in which modern Greek identity rests. They cite, for example, the way the material culture of the archaeological record is deployed in moments of national significance, as in the 2004 Olympic Games (Plantzos 2012).

Criticism is leveled also against the 20th century archaeological practice of approaching material culture with a sort of metaphysical reverence (Hamilakis and Yalouri 1999). Platzos (2014) describes the ancient past in Greece as an ideal and a counter-ideal, in a quest for authenticity. Accordingly, the formal disciplines of archaeology and classics, brought by the western intelligentsia are perceived to have been the inauthentic terms of giving voice to the past, an alien, elite pursuit presented across a range of forms in modern Greek art and literature, including filmmaking. "it had become abundantly clear that philhellenism, especially its German variety, was a corollary of (other people's) nationalism: Greek ruins had been appropriated throughout the nineteenth century by foreign archaeological expeditions, with the French and the Germans at the forefront" (Plantzos 2014, 149). Via this indigenous resistance to the colonial powers, according to the same author, there came the "crypto-colonialism" of the Greeks, which stressed a metaphysical connection to the land and its past, an authentic representation that could not be reduced to the prescriptions for a reified, modern Greek identity.

The response of the subaltern, in a very European sense, alien both to Said's Orientalism and to Bhahba's notions of resistance through the creation of forms of hybridity, assumed instead a form of resistance, in the form of allegedly authentic representations of the past. These were both different from the artificial European representation, and due to its "glorious" past, superior. Plantzos (2014) criticizes this alleged 19th century "cryptocolonialism" of the Greeks, which purportedly carried on to the 20ieth century.

These academic efforts do not simply ignore other contemporary realities of how the cultural heritage gets enmeshed in politics of appropriation that deploy cultural heritage in strategic ways according to contemporary political agendas and pursuits (Kotsonas 2015). Attempts at deconstructing the so-called national imaginary gained a momentum in recent years, even as the state of Greece per se was unraveling in very practical terms and with tangible effects. Under extreme pressure, the social and state apparatus began shrinking, while collectivities and NGOs started assuming several of its functions (healthcare, basic provisions for vulnerable groups of the population). What was the symbolic capital left for a population under extreme stress in economic and biological terms, while also forced to constant self-analysis and self-exploration, given the international mediatic onslaught against it? Plantzos (2012, 159- 
160) uses the well-known episode of C. Lagarde commenting on the poverty of the Greeks contemptuously - the poverty affected by the IMF over which she still presides - so as to offer an ivory tower view of how the Greeks have supposedly internalized perceptions of "civilizing the world."28 A less subjective account of the comment, mindset and practices it conveys, would place emphasis on the detrimental effects that the IMF market-style "management" of the crisis in Greece and on its managerial style increasingly presented as a universal template for value systems of less society, less culture, less civilization.

\section{Digging through the Crisis}

Massive overhauls in the structure and staffing of the Greek Archaeological Service, the state service entrusted with the discovery and preservation of archaeological heritage, undermine many critical aspects of its functions.29 The ephorates (the divisions that make up the Archaeological Service) have a monopoly on all aspects of heritage management when it comes to the archaeological record. Several ephorates and museums across the country remain understaffed and with inadequate protection, archaeological sites remain closed due to the lack of personnel and several archaeologists have been given responsibilities far surpassing the hours of work for which they are employed.

The under-staffing of museums and ephorates, despite the exorbitant rates of unemployment among archaeology graduates, led to various suggestions as to how the issue should be addressed. Some foreign academics suggested that part of the management can be relegated to the private sector, a huge taboo for a country that maintains a centralized, public monopoly on the national heritage management. Addressing this "taboo" of private involvement, rooted in fears of colonial-style "appropriation" of archaeological heritage by stronger nations (as happened in the 18th or 19th centuries) and enshrined in law would seem however to antagonize public sentiment on an issue considered of pertinent national importance - the archaeological heritage. The recent case of the ongoing discoveries at the Macedonian funerary complex of Amphipolis (Hill of Kasta) that remained center-front in media coverage and public debate from mid-2014 through part of 2015 highlights some of the issues that such an approach of countering the economic crisis would generate. In the eyes of the public, it would be inconceivable to allow the protection of a "national treasure" to a private entity. The Greek government in power in 2014, on the other hand, made a point of how it considered that particular archaeological site of national importance. Such manipulation of archaeological discoveries for political purposes (spectacular publicizing of discoveries and daily newsreels on the issue), masquerades a very different reality, one of diminishing investment in heritage management and academic research, of which the public is not always aware.

While in northern Europe, archaeology needed to adjust to the profit-driven conditions of the market, with the development of private agencies, such an outlook generates images of dystopia in Greece, and not without reason given the local context. On the other hand, the so-called "foreign schools" (foreign archaeological institutes of research and fieldwork, active in Greece) conduct fieldwork under the formal supervision of the Greek archaeological ephorates. This amounts to practical aid in the cultural heritage management, on the level of excavations and publication. However, the Archaeological Service, as the basic service of antiquity management and promotion structure in our country, has been shaken by terminally alarming and continuous structural (and sweeping) rearrangements that have have alarmed even foreign schools, since archeology excavation programs depend on the smooth functioning of local ephorates.

A different suggestion for addressing the increasing under-staffing of the Archaeological Service has been the introduction of community archaeology, a concept foreign to the mentality and practice of archaeology in Greece, but existent in north-western Europe, e.g. in the UK, Belgium and the Netherlands. Community archaeology would theoretically provide a response to the demands posed by severe cuts and mass layoffs of archaeological staff, a taboo of private initiative, and a means to engage the public in a productive way that also has the potential of counteracting the effect of non-scientific, popularized accounts of the past. The latter are disconcerting given the rise of extreme forms of political representation (far-right parties), with their strange concoction of populism and nationalism mingled with glorified accounts of the ancient past. What are the ethical dilemmas, however, in delegating the excavation of sites to amateur archaeologists (conceivably pensioners and schoolchildren), when many trained archaeology graduates, career archaeologists and academics, remain unemployed or are by the circumstances forced to choose a different career or emigrate? Some of these concerns will remain of academic interest only, as any such change requires first political initiative for which interest is thin, when the governmental agendas show different priorities. Potentially, however, over the long term, some of these debates and the distilled ideas they generate can infuse policy-making affecting some level of change. Despite continuous staff reductions and removal of services, the neuralgic area of archeology continues to serve the country's needs for cultural management thanks to the work 
done by archaeologists, their loyalty to their profession and personal sacrifices.

\section{Impact on Researchers: The Itinerant Academic}

Scholarship, teaching is a vocation, a love and an ideal. From this derives much of the self-sacrificial tone surrounding work in the humanities, tied to the "sanctity" of producing and disseminating knowledge. This widespread perception explains the little resistance to the sacrifices entailed in following an academic career (Bal et al. 2015, 65; Lorenz 2015, 7). Hardly peculiar to a European context, this universal (almost) template was until now widely tempered by notions of an afterlife, i.e. the attainment of basic living standards while working in the humanities.30 These are concerns that are encountered even among the most privileged classes, members of which are still subjected to the inherent, structural violence of the system.31

The mass increase in the number of doctoral titles obtained in OECD countries, with an annual average rise of 5\% per year, during the last decade alone (2010-2015) (Papari 2015) erodes the basis of this model, in tandem with the imported neoliberalism. The increase in the availability of highly-qualified personnel contributes to the "precatarization" of young academics. Standing's (2014) precatariat, coined as a portmanteau to denote the precarious living conditions created by the neoliberal flexibility of the labor market since the 1970s, aptly reflects the life conditions of many academics.

The severe repercussions of a labor market that transfers the employment-related risk and insecurity to the employees/workers can be seen in aggravated physical and mental health, financial insecurity without safety nets and social isolation, stressed from across the EU (Papari 2015; Lorenz 2015; Halffman 2014). The prevailing employment conditions, be it in teaching or in research funding, prescribe a constant reality of insecurity, casualization of work and mobility, which has serious repercussions not only for the personal lives of those involved, but also for the quality of the research per se. In the case of the EU grant "Marie Curie," for example, early career researchers are required to move to a different country from the one they have been working thus far, hence elevating mobility to a proxy for desirability and excellence - regardless of the fact that increased expectations of mobility can obviously have adverse effects on research output. With academics not belonging to any institutionalized professional collectives, neither health (Bal et al. 2015, 50), nor income or other security is respected. In tandem, the much-celebrated urban nomadic lifestyles expected of academics (alias for "European integration" and "harmonization") do not provide any sense of long-term security, as the academic finds himself/herself outside the regular labor groups (Papari 2015), thus being reduced to isolation as a citizen, and more than often, as a migrant. Unionizing thus becomes impossible due to the dispersed, scattered, ever-temporary and mobile nature of employment of the labor force concerned.

Insecurity due to low salaries and temporary contracts, with newly-invented academic titles to match them (e.g. "teacher," "instructor"), form an aspect of this. While job titles change and longer-term job security becomes a dream, academic positions continue to nevertheless demand full academic credentials, with little reward in terms of covering basic material needs. Compounding problems at a time of crisis, unemployment for a certain length of time is a given.

This is aggravated by the strict conditions on the employment of post-doctoral researchers, beyond obvious qualifications.32 Early career fellowships, nominally designed for young academics, often come with restrictions on years after the obtainment of a doctoral title or on age. Yet these do not take into account gaps of unemployment due to the constrains of the labor market, thus diminishing even that short-term, temporary employment avenue to many. This being empirically common knowledge, a recent study estimated the average of the post-doc/trial' period after the obtainment of PhD to 13 years at Dutch universities (Halffman 2014). Young people are then left with academic credentials, but lack of long-term academic posts and the inability to apply for lower-ranking posts for they do not meet the strict age criteria. Extreme overspecialization already creates a limited pool of jobs stretching across the globe. These restrictions are often caused by over-regulations that have outlived their original purpose of safeguarding a position for new researchers who need a boost at the start of their career. They were clearly devised in periods with different economic circumstances, and do not apply in an economy where securing a reasonably safe (not even tenured) position may take decades. It appears that policy on funding has not caught up with reality.

In the end, universities are those that benefit from these conditions in the labor market, which leads to the "casualization" of academic personnel. Through the creation of a global pool of "casual reserves" to draw upon, universities afford to keep offering short-term, low-paid contracts, which translates into a life of insecurity and 
sacrifice of current income for a future stability on the part of the academic precatariat. This employment status masks the adverse effects of unemployment under the mantle of temporary employment, transforming the academic career into a globally-stretching, hierarchically horizontal network of occupational status, whereby one cannot move up the academic ladder and is often found in perpetual precarious labor conditions (Papari 2015). These casualized researchers and teachers have little leverage in negotiating the contracts they are offered. In this system, (career) failure is then seen as personal not institutional (Bal et al. 2014, 63), due to lack of competence. In their incisive critique on the class struggle in archaeology in the USA academic and cultural heritage sectors, McGuire and Walker (1999) pilloried the precariousness caused by this neoliberal set of relations, speaking openly of systemic exploitation.

The widespread sense of precariousness, felt globally in the field of archaeology, led to a recent volume on how to address the scarcity of academics jobs and how to move onwards to the "real-world" (Killebrew and Scham 2015). The term "real world" is unfortunate, of course, since entering academia and the effort it necessitates to remain employed are very much part of the real world, and one that due to its international nature demands a lot of skills and resources while it offers limited security on all fronts, especially in relation to other, more "set" professions. While the expectations of quality of research is often set in starry-eyed expletives both by the EU and national funding bodies, the quality of provisions hardly provides the conditions that would enable "excellence in research."

In many ways, such expectations from researchers work only on a platonic universe of ideas - a parallel universe where the academic need not move to a new country, negotiate brand new living and citizen conditions, need not learn a local new language or civic state administration/bureaucracy at the very least, need not manoeuvre new social and political contexts, need no social interactions or have no longer-term expectations - in fact, his/her entire life can be measured alone by (thus, reduced to) his/her scientific research output, assessed by the output of publications, which in turn are based on the quantification provided by statistically invalid metrics of journal rankings and the like. More importantly, a parallel universe where the academic, often within the first two months of taking up a position and starting a new research project, is in no need to start writing a new grant application, as is currently very much the case.

The contingency of national contexts aggravates the wider conditions of employment. In Greece, for example, academics face a harder reality than a lot of their peers, despite the presence of several Higher Education institutions in the country relative to its population size. Overregulation in the sector and employment that follows extreme bureaucratic procedures were the norm even before the crisis, which has generated a new wave of obstacles. According to the Greek Statistical Service data, in 2010 the number of doctoral candidates was 23,853. In 2014/2015 almost 950 doctoral theses were submitted to Greek universities (Papari 2015). In a country where the budget relegated to research remains negligent due to the constraints imposed from outside, the main option for doctoral holders is to enter the application rounds to European and US institutions. The status of private tertiary education remains legally ambivalent, and creates little potential for career advancement, especially since humanities are rarely offered in the more market-oriented curricula of these private schools. Even the most recent innovative initiative of the (public) Open Hellenic University is not an option, as in practice staff members are sourced from the established academics of the public universities in the country. The result is that preemptively new doctoral holders are excluded from any chance to attain a position (Papari 2015).

On the institutional level, Killebrew and Scham (2015, 234-237) note that current doctoral programs have little evolved since the Middle Ages, suggesting that their necessary restructuring takes into account transferrable skills for careers outside academia. Taking as a departure point the insecurity that the neo-liberal policies of higher education lead to, they suggest the introduction of teaching modules that lead to technological proficiency, "reallife leadership," and management skills. Reinforcing this pragmatic approach, they call for academia itself to begin evaluating positively career choices and experience outside the academic sector.

On the personal level, Papari (2015) notes that these circumstances create "personal frustration, sense of thwarting, futility" creating doubts as to the value of repeated sacrifices. In the end, as many authors point out in Killebrew and Scham (2015), while it may difficult to cut ties with something one loves deeply and to which has devoted years of their life, there are other options: In Tarler's $(2015,276)$ words "But you are not a one-dimensional person." Indeed, exiting academia is an option, and one offered recently as a form of resistance to the neo-liberal model (Halffman and Radder 2015, 171). Its applicability, however, depends on the local and national context. What are the consequences if someone does not opt for that? A typical, real life narrative is given below:

I am lucky, in the sense that, unlike many colleagues and friends, I have not (yet) experienced long periods of unemployment. On the other hand, I have yet to discover the added value of the post-doc experience. My first position, held overseas, in 
the USA, was a one-year position, meaning that the first thing I had to dedicate myself to, was a new batch of applications, to secure a position for the next year. This left me with little time for research or publications. In addition, the absence of a coherent mentoring system, or further opportunities for $\mathrm{cv}$ building, such as organising a workshop, teaching a class or even start a reading group, meant that, academically, the experience had no significant effects upon my career. Next, I obtained a position in the new "promised land" for academics, Germany, back on the European continent. This time, the position came with a mentoring program, specifically aiming at enhancing the postdoc experience. Given that it is a two-year position, even with a possibility to extend it to a third year, I can at least relieve myself, for some time, of serial application writing, and actually do research and publish. I was even able to propose my own course to teach. The other side of the coin is that the stipend does not exceed the official minimum wage. Given that it is paid as a stipend and not as a true wage, I have to provide for my own health insurance (obligatory, with rates normally charged to the liberal professions) and pension scheme (which I can obviously not afford). The size of my stipend does not allow me to save money to bridge gaps between positions or save for retirement. Thus, I fear to be on the brink of poverty, if not soon, then likely later. Apart from struggling to pay the bills, I can hardly afford to buy books, or travel to conferences, which means that, again, my position obstructs rather than enhances my career development (Lieve Donnellan).

\section{Value vs. Valorization in the Humanities}

\section{Perceiving valorization: Views from archaeology}

In this climate of increasing financialization, research is tied to its economic output. Alas, the humanities are significantly disadvantaged. Thus attempts to remain "societally relevant" as academics are crucial to survival yet distorted by the perspective through which relevance is assessed. For example, the attempt to render archaeology and related disciplines relevant has resulted in several folly pursuits and distortions of the real value of the humanities. Hotlfof (2007) discussed three main trends in archaeology, so as to render their use a conscious choice. He labeled them the "Democratic Model," the "Public Relations" Model and the "Education Model" (Hotlfof 2007, 150).

Holtorf's (2007) discussion of how archaeologists project to the public their research is instructive. The "Democratic Model" refers to - one may argue - the original approach in the field, the view that the archaeology's value consists in producing knowledge for the enlightenment of society, serving a collectively better future. His criticism comes fiercely:

To define public education in such terms is to presuppose an infantile condition among its audience. It can mean to assume that prior to education a void exists in the citizens' minds where knowledge of the past should be. Or it can mean.... really, not genuine education but rather re-education. Either attitude is patronizing towards any fellow Homo sapiens (Holtorf 2007, 152).

Thus, the attempt to disseminate knowledge to the public about the past, gained through scientific enquiry, is construed as being open to patronizing and condescending overtones, depicting the representation of the past as the prerogative of archaeologists and historians. Why should that be construed as patronizing? Do archaeologists feel patronized when informed about progress in fields in which they have no competence? Does the discovery of the existence of gravitational waves in the universe make adults of the Homo sapiens species feel patronized by physicists? During the course of an adult's life, almost everyone defers to an expert in some area of life, be that medical care or legal service or the building of a house. Does attracting expertise by those who have the relevant training and capacity in one field render the rest victims of condescension?

In discussing the "Public Relations Model," which he equally considers ethically untenable, Hotlof opines that it advances the social milieu of the archaeologists themselves. The former considers that publicity, even through channels that misrepresent the discipline (Hotlof 2007, 155-157), competes in an arena of commercial mechanisms.

Discussing the "Democratic Model," the author refers to the way that indigenous voices, narratives and memories are included in the representation of the past (in contexts where this is relevant). By extension, Hotlof (2007, 157-158) asks "Why should ordinary but non-indigenous citizens be granted any less attention?" (Hotlof 2007 , 161). The answer is one of context. Hotlof's experience comes mainly from the Scandinavian context, where the indigenous voice may be relevant, and thus by extension, that of the "ordinary but non-indigenous citizens." He argues for the "right balance between public participation and the possibility of creative self-realization for as many people as possible on the one hand, and the need for the state and its agencies to ensure that competent decisions are taken in all areas." This presupposes a well-functioning state, and of course, a democratic one.

From a European context, this approach raises some questions: is the stakeholder the EU, whose competence 
is that of the market, as a de facto priority, or perhaps the nation, whose budgets can be relegated to extra-state bodies whose only competence and interest is in fiscal concerns? Holtorf $(2007,152)$ ends with the alarming: “... in one way it does not matter very much if our knowledge of the past is accurate or not," considering knowledge of the past meaningful only in as much as it indexes one's social class and lifestyle. Trying to qualify this strong, "not fully-developed" argument, he adds that in cases such as the long-term environmental trends, knowledge of the past does matter. The author seems to fully disregard how knowledge of the past forms group identities, not on the level of lifestyle choices, but on the level of national ethics, political views and the like. Indeed, the view reflects rather a more aloof and until-recently cushioned reality of life in a Scandinavian country. Such views, among archaeologists themselves no less, are worrisome in the extreme. Yet a watered-down view of the world with all the misinformation it begets, becomes the first tool of anyone wanting to misdirect public opinion.

The questions of why all this relativism in the humanities of the past and self-undermining becomes imperative. Why all this discourse about the artificially authentic knowledge being passed on? Isn't this after all what disciplines across the spectrum of the scientific fields do? Produce knowledge that can be passed on, with the caveat that future knowledge may render it amenable? With the caveat that some of this may turn out to be partly wrong, or entirely wrong even, susceptible to scrutiny? With the exception of the contexts where this is truly appropriate and needed (e.g. in colonial contexts) should, for example, the public be engaged in the representation of the past? Would it be summoned to aid in the descripton of a new galaxy when astrophysicists present some new evidence? Should there be a public consensus on the nature of a newly discovered planet, one that accommodates the public's interests and opinions and perceived needs? The question is hard not to ask. The answer boils down to the value of the disciplines, in contrast to the easy packaging of "valorization."

\section{Inherent Value as Social Capital}

Current perspectives in archaeology may emphasize the ways that practitioners in the field of humanities represent and communicate to the public their knowledge about the past. Polyphony, relativism and the "ownership" of the past have emerged as pivotal subjects (e.g. Scarre and Scarre 2010). In fields concerned with the study of colonial contexts, it is fundamental to be aware of the hegemonic relations in the production of "knowledge" through structures that are embedded in the state apparatus. Yet humanists have been thrust into the position of not being allowed to challenge the state apparatus - by contrast, they need to appease it and flag its economic potential.

Increasingly archaeology has been packaged as a cultural product ready for the consumption of an elite. It is the marketing mechanisms that then determines the valorization of the discipline, making it dependent on whether it can compete in the arena of entertainment industry, contributing to one's lifestyle, or to the tourist industry. This is the outcome of the financialization of universities, and of their attachment to the neoliberal principles. In such a climate, the humanities do not serve their purpose, rather they serve the status quo, failing to critique and challenge the rationale, fairness and integrity of its decision-making, and slavishly relying on it for the continuation of their existence through state funding or more perilously, though commercial mechanisms.

Yet archaeology is not a cultural product, a small extra something an affluent family enjoys on a Sunday morning. The humanities as a whole are not some added airy-fairy pursuit that wastes resources unless a tangible economic benefit can be linked to it. Humanities are central, indispensable to a society that needs reflection, critical thinking and cultivation to exist in a democratic, society that values participation and collective decision-making through the careful selections of its representation bodies. How can the humanities help towards that?

Let's take archaeology, for example. It is a discipline concerned with the whole spectrum of past human experience, from early human origins and cognitive development to the emergence of the first sedentary societies, the introduction of agriculture, the invention of ground-breaking technological advances such as writing and the wheel and the development of symbolic systems, which changed the course of history, setting it onto a trajectory that led to the present as we know it. And this is specifically where the value of archaeology lies - in its ability to shed light onto the past, on "where" we came from as humans and "how" our ancestors thought and lived, so as to better understand our present and the future as human societies. This is even more crucial for regions and periods of the world for which no or scant historical sources exist: without archaeology to fill in those preliterate or scantily known through textual sources periods of human history, our knowledge of the past would be teemed with confusing, bewildering gaps. This critically endangers the ability to fully grasp the roots and evolution of humanity diachronically from a global perspective, understanding its bearing on the present through the accumulation and exchange of norms and modes of social relationships that transcend neatly-described chronological periods. Pertinently, a lack of knowledge 
of the past or its misrepresentation harbors the true possibility of it being manipulated for political or economic ends, a reality that we have seen - and continue to see - repeatedly across different periods and regions of the globe. As such, the past is inextricably woven into the present - because the present would not exist without it and in many ways it is incorporated into it - so knowledge of the past does not have value only for archaeologists or historians alone but for the society as a whole.

It is this value that humanities, and especially fields such as anthropology, history, archaeology and classics bring - the very disciplines that suffer the most. The most severe repercussion in the long-term will ineluctably be the shrinking importance of these disciplines within universities and their status in the public domain. While university departments, research groups, infrastructure and learned practice take decades to develop a certain standing, tradition of research and level of expertise, radical overhauls as a knee-jerk response to a temporary or passing fiscal crisis can have lost-lasting results, effectively resulting in the disappearance of whole disciplines from university teaching and the loss of public collections.

Policy-makers, especially through regulations on the allocation of funding, can have an impact on the paths that research takes or on whether certain fields will continue to exist in the future. While on a personal level regarding practitioners, these policies have severe repercussions creating a negative environment of (professional) uncertainty, the results cumulatively are potentially catastrophic for the future of fields in specific countries. Massive overhauls and cuts ineluctably lead to many seeking careers outside their chosen field or moving abroad, a cause of "brain drain" that is already being recognized as a major plague in countries such as Spain, Portugal, Spain, Greece and Ireland. Yet more pertinently, the shrinking or actual destruction of institutions that generate, preserve and disseminate knowledge will have catastrophic results on society in the long term.

Egregious decisions towards a society lacking the buttress of critical thought can only exacerbate the rising nationalism across the continent, the pitying of one social group against the other as a response to the socioeconomic melt-down. Yet the full scale of the consequences will become apparent only in several years. When both national governments and supra-national bodies cut funding for the humanities, the result is not just less "culture" to consume, but also less civilization in a society. And decisions as to this should not be allowed to be determined by the passing government or at the precept of a bureaucratic elite following its agenda, far-removed from social, national or cultural needs. That which gets demolished within a few years - entire departments, and with them the research, the knowledge, the contribution to society - actually took decades to build. Once gone, they are gone. A new government will not just put them back in place on a whim. A corporate-managerial attitude to universities, education and research may create enough surpluses to have new buildings constructed for a campus, but will not go far in terms of the cultivation of those they purportedly aim to educate and enrich.

\section{Responding to the Neo-liberal Model of Disfiguring Society through Eroding Education}

Some of the immediate consequences of the financialization of the universities and research can be readily seen. The deficiencies of humanistic education across the EU can be seen in the immediate responses to the economic crisis across large social segments: from increased forms of nationalism, chauvinism and xenophobia to distorted understandings of the competences and faults of the EU, public complacency on how one's own actions and state policies affect different social/national groups, as well as media propaganda, state and supra-national arbitrariness.

Academics should be the first line of defense against the erosion brought by the neoliberal measures and not only because their own professional status or livelihoods are put at peril. "The response to the cynicism" of the neoliberal labor market is the recognition and redefinition of the social role of the university in Europe as "a vision and a public good" that will create a knowledge-based society for the prosperity of the 21st century (Papari 2015). This type of university will support fundamental research, "a vital resource [from which] we can draw upon if the future turns out to be totally different than our short-term extrapolations" (Halffman and Radder 12015, 76). Such a society should keep state power and other forms of authority in check, respond to societal needs with wisdom and forethought and face challenges cognizant of what came before and of the potential offered by technological and scientific advancements, without the excesses of the past.

The mere addition of further funding is not a panacea for European universities. As Papari notes (2015), what is crucially needed is policies towards a creative role for the university where it:

will listen to and will observe on a local and universal level the developments taking place and will relate and be diffused to society, utilizing the new scientists and researchers ...be that in teaching or in public research projects that will widen its service, while the researchers will demand equal participation in the global scientific community. 
Both the need for academia to be societally relevant and the need to value those who work in it are stressed. National and supra-national policy changes will need to be directed towards this aim. Short-term suggestions for the amelioration of these conditions on a microscale can include affiliations of independent researchers with foreign institutions. Whereas this does not provide a solution in the long-term, or even in the short term for the profession as a whole, it may give some respite to individuals, who in the long term may be able to create their own groups, should funding become available. There are several cases in science, for example, demonstrating the potential of implementing such ideas.33 In the end, though, such initiatives cannot replace a restructuring of the funding mechanisms of the humanities, which if it does not come through sensible national policies, should come from forms of resistance from within the academic community. Several forms have been outlined in academic counteroccupation projects (Halffman and Radder 2015, 180-185).

\section{Valorizing cultural heritage: the past, its material remains and the collective future}

How should we demonstrate the value of cultural heritage as a resource of culture and civilization? Archaeologists are often seen as merely custodians of dead stones and their work and its output are often relegated to the dustbin of irrelevant to modern life subjects (and according to some opinions, objects too). In this sense, the cultural heritage loses all of its meanings, including most importantly, as a conveyor of education and culture. Alternatively, it is perceived as the pursuit of an exclusive and privileged elite, or worse it is consciously used for the promotion of nationalistic agendas.

How can this situation be addressed, so that the promotion of cultural heritage moves away from these hindrances? Since often heritage management practitioners cannot escape such trappings, and easily fall into such discourses that alienate segments of the society, the aim would be to develop professional development platforms through which heritage management practitioners can be better trained in understanding some of the deep-engrained biases instilled in their earlier education and training and in how to promote cultural heritage in a healthy and productive way that underscores its value as a knowledge resource for all. This, in the longer term, will be poised to influence policy-making at the national level, so that the entire discourse surrounding cultural heritage will take into account its universal relevance. This could be achieved by organizing seminars and series of workshops aiming specifically at how cultural heritage practitioners communicate the results of their work to the public, avoiding, for example, unfortunate popularizations of their work. Such workshops would focus on communicating to the public, in a responsible way, conscious of its potential biases, the work and importance done by cultural heritage practitioners.

Current perceptions of cultural heritage in Greece offer a compelling example, but also suggest ways of how to better the connection of society with cultural heritage. In a rapidly changing Greek society, which becomes increasingly more mobile, better educated and international in outlook but also multi-cultural, with the influx of populations from different countries and even continents, the presentation of cultural heritage as the tangible aspect of a sacrosanct discourse of a glorious ancient past (as taught at schools) is turning the perception of ancient cultural heritage into something arcane and even obsolete with little relevance to the lives of adults. Quite commonly, however, this imaginary is appropriated in unscientific ways for supporting nationalistic discourses that are plaguing understandings of the past as well as of the present, attracting the less educated and older segments of society. Effectively, for a large part of the population, interest in ancient temples, theatres and tumuli is considered to be the arcane past-time of a dying intelligentsia elite, or, in a diametrically opposite way, it becomes the fixation of an uncultured and easily impressed crowd through popularized accounts in the media, hungry for past "glories." When revived with enthusiasm, it is often in association with the internalization of the sacrosanct discourse of classical Greece and "our golden ancestors" - in a sort of establishing metaphysical connections with the past - that can be seen in the reaction to the intended re-burial of the Altar of the Twelve Gods in Athens in 2011 (which amounted to full protests taking place in Athens in a well-intended but ill-conceived attempt to "protect the past"). The flourishing of TV channels, magazines, books and other publications presenting irresponsible and sensational accounts of the ancient past is another, more malignant manifestation of this tendency to relate unscientifically and unproductively with the cultural heritage as a source of modern fixations, not of useful knowledge. Alternatively, cultural heritage is deemed entirely irrelevant to a large number of people living in Greece whose backgrounds are to be found outside Greece, and who thus cannot relate to a discourse of "golden age" ancestors, usually because it is promoted as such by heritage management practitioners.

How can we engage society with the humanities, as a source of valuable experience and powerful knowledge, so that the values of the discipline get unlocked? Developments that can already be seen in fields such as archaeology and ancient history (e.g. "popular science" magazines) have gained impetus among the wider public, casting aside 
more legitimate sources of learning about the past.

Rather, the engagement of the public needs to showcase tangibly the role of cultural heritage as a valuable resource of culture and civilization for contemporary and future societies. Such goals should be permeated by the conviction that the preservation and promotion of the humanities and our cultural heritage occupies a central importance in the education and cultivation of communities and society as a whole, especially at times of rampaging economic and social crisis that amount to, and underlie, a crisis of values. With informed knowledge of our human past, individuals, communities and societies can gain a holistic understanding of the depth of human history, of not merely events but also intellectual currents, achievements, mistakes and their repercussions into the present that can increase their resistance to the vicissitudes of modern life, but also tangibly, foster new pathways of sustainable economic development. The past can thus become alive with significance for the present, as an invaluable resource of human knowledge for comprehending problems, solutions and preparing for a better future.

In practice, this entails the protection, conservation and valorization of cultural heritage, the management of which depends on individual competency, local contexts and structures, as well as national agendas and international policy. To contribute positively to the goals listed above, given such a varied environment within the EU that often works circuitously in its impact on cultural heritage, initiatives should follow, broadly, ways of interventions that cover the main categories of needs and challenges that cultural heritage now faces.

Focus should be placed on enriching capacity building for sustainable cultural potential in pragmatic ways and developing and disseminating expertise for addressing multivariate challenges and threats that endanger heritage globally. Grassroots approaches are far and few, but some have shown already a momentum.

The Initiative for Cultural Heritage, for example, an international organization, is already working along the state apparatus for the valorization of the cultural heritage in Greece through capacity building (educational and training programs), while developing and delivering cultural heritage management with international reach. Building expertise through workshops, courses and seminars, as appropriate, emphasizing the 'universal value' aspect of cultural heritage and its relevance for contemporary society, independent of biological ties and nationalistic concerns, can result in promoting a healthier connection with the past and its relics, without the fixation, obsession or indifference to it that form part of the mosaic of contemporary attitudes in Europe.

Alternative ways of attracting funding for promoting cultural heritage management, on the potential of utilizing private investment in the promotion of cultural heritage should be considered. There have been cases, for example, where important archaeological sites developed by private investment following rescue excavations in highly urban areas, e.g. the archaeological site of the Iron Age port and cemetery musealized in situ under the Millennium BCP bank building in Lisbon (Portugal), in an underground exhibition space that also houses a museum, with daily guided visits.

Lastly, the economic interest of the cultural heritage is well recognized, in terms of attracting heritage tourists but also in terms of promulgating a broader "cultural" image. Building management capacity need not reduce cultural heritage to a folkloric touristic package. Instead, it should take into account current international framework (international policy on heritage protection, illegal trade in antiquities in Europe), cultural heritage infrastructure, local needs and academic research. An idea would be to combine in public projects tangible with intangible heritage. Intangible heritage is recognized increasingly as an aspect of heritage that needs to be safeguarded and promoted. This aspect can easily facilitate engagement with local communities, especially in rural areas distanced from museum and other events organized to celebrate cultural heritage. Capacity building for its sustainable economic potential, in ways that make it relevant internationally, can span many areas of competence, from linguistic idioms to traditional music and architecture to folkloric narratives (oral poetry, legends, narratives).

\section{Conclusions}

No easy or straightforward solution exists that solve problems over a series of interrelated issues, across $28 \mathrm{EU}$ state members. A start will be the realization of the degree of erosion of the meaning and value of the humanities caused by the neoliberal system of the financialization of the universities. Reinstalling the potential of social value into policy should begin with a shift away from market-inspired fixations and obsessions with metrics, quantifications, economic output and financial valorization that underline the amnesia of purpose of it all: which is to produce knowledge that is central to the function of a well-governed, society formed by a body politik with critical ability. It 
is pertinent to remember that knowledge currently produced will be susceptible to change in the future, to the degree of being fully discarded. At a time of multiple crises plaguing the social, economic and democratic fabric of the EU, only a citizen body with critical acumen can survive political and economic decisions that are being taken with it in absentia. And critical acumen cannot develop in a void of knowledge about the past or with the fetishization of the market.

\section{Endnotes}

1. See for example how the euro system TARGET 2 (Trans-European Automated Realtime Gross settlement Express Transfer system 2) of the European Central Bank operates (Vaorufakis 2014: 127-128).

2. The notion that a nation's economy is amenable to the profit-increasing games played by private companies (credit rate agencies), which by fear-mongering alone playing to their own interests' tune, can increase a country's debt (translating as increased unemployment, reduced healthcare provisions, asphyxiated welfare state, more suicides and so on) seems deeply absurd to many. Suggestions around 2011 from high echelons in the EU to establish European credit-rating agencies as a bulwark to faltering standards of risk management in financial institutions and accountability have since succumbed to oblivion.

3. Žižek on the impossible dialogue between the Greek government and EU institutions in 2015: "Strategic decisions based on power are more and more masked as administrative regulations based on neutral expert knowledge, and they are more and more negotiated in secrecy and enforced without democratic consultation", http://www.newstatesman.com/politics/2015/07/ Slavoj-Zizek-greece-chance-europeawaken

4. The debt of Greece was 298.5 billion euros (129\% of GDP) in 2009 (before any so-called aid to Greece) and in 2015 it stood at 322.5 billion euros (a whopping $175 \%$ of GDP), while the country continues to suffer a contraction of economy and mounting socio-economic problems.

5. The admission of a mistake in the mathematical formulas used by the IMF to evaluate the impact of the austerity it administered on Greek society occurred "gradually," first in the World Economic Outlook (2012) of the IMF, and then in a 2013 report by the chief economist of the IMF, Olivier Blanchard (Valavani 2015: 36-37).

6. The potential of gain in an investment is tied to the risk of loss. With German bank investments in Greek bonds being jeopardized, however, the enforced "loan agreements" to Greece entailed both the expectation of profit and the obliteration of any possible loss. Since the failure of financial institutions would inevitably affect the welfare of nation states, a just approach would have been for both parties of the investment to be held culpable. In reality all moral blame was pointed at the Greek state despite the predatory lending of German banks, and in practice it was by far the one party sustaining losses through the EU response measures.

7. On the prescribed down spiral of the Greek economy by the EU/IMFE, see indicatively Pavlopoulos and Vassalos (2015) and Douzinas (2013). Specifically, for the economically irrational policies followed by the EU with the first two "loan agreements" see Varoufakis (2014: 25-370).

8. Indicative of the trend is an article by Michael Wolffsohn (professor of history at Universität der Bundeswehr Munich, entitled "Volksverführer - order is das Volk doof?" (Demagogue - or, is the nation stupid?") with reference to Greece (16/2/2015), handelsblatt.com

9. Between 2010 and 2015 new bills and legislature were voted by the parliament without due procedure, after delivered by the Troika. The passing of the second MoU in February 2012, with the area outside the parliament in flames, strong protests and episodes and the MPs requested to vote on a 500-page technical and legalistic document so that "the country would be saved," thereby indebting it for generations (with explicitly stated no provision for a debt forgiveness in future generations) is instructive. The text was given few days in advance so that it would not be read before being voted in the parliament and without the preparatory stages that Greek law requires.

10. The secretariat-general of the EU Commission allegedly gave the following response to the then finance minister's Yannis Varoufakis quest for legal advice on being excluded from the eurogroup of 27 June 2015: “The Eurogroup is an informal group. Thus it is not bound by Treaties or written regulations. While unanimity is conventionally adhered to, the Eurogroup President is not bound to explicit rules," http:// yanisvaroufakis.eu/2015/06/28/as-it-happened-yanisvaroufakis-interventionduring-the-27th-june-2015eurogroup-meeting/

11. The very reason that such a high number of eurogroup meetings was invested in trite matters such as the VAT on Greek islands, while the EU was facing 
the Ukraine crisis and the refugee crisis creates plausible questions and indeed assumptions about the real causes behind these protracted meetings over subjects that on a European level were at the very least insignificant.

12. For example, the 1 st $\mathrm{MoU}$ with the Law 3845 ("Measures for the application of the support mechanism for the Greek economy by Euro Area Member States and the International Monetary Fund") became law of the Greek state on $6 / 6 / 2010$, even though the "loan agreement" that was part of it was never discussed in the parliament, as it is stipulated in the Greek constitution. Subsequently on 1/7/2011, Law 3986/2011 was discussed in the parliament so that additional "urgent" austerity measures would be voted in (the so-called "Medium Term Framework of Fiscal Strategy 2012-2015"), which was passed with 155 MPs voting in favor, although a parliamentary majority of at least 180 votes is required as stipulated in the Greek constitution. See e.g. http:// www.ilo.org/dyn/natlex/natlex4.detail?p_lang=en\&p_ isn $=84784 \&$ p_country $=G$ RC\&p_classification $=01.06$

13. For the roadmap to the referendum and the signing of the Third MoU, see Kouvelakis (2016).

14. The session in the parliament was in a special committee of public good companies and required $2 / 3$ members majority to approve it (Valavani 2015: 98100).

15. http://www.futureofhumanities.eu/humanities-and -social-sciences-research-budgetreceives-significantcuts-under-horizon-2020-framework/

16. Saltini-Semerari demonstrated the "bottleneck effect," using as case studies three European countries (the UK, the Netherlands and Germany) in order to assess the postdoc application process requirements and outcome, focusing "on requirements, assessment process, resources offered if successful, and successful project oversight", showcasing the problems in "the balance between these different aspects and their reciprocal interaction."

17. For a discursive analysis on the meaning of the notion "quality" in the goal settings of the convention leading to the formation of the Bologna process at transnational settings, see Saarinen (2005).

18. The Valletta Treaty (2007) confers a central role in the management of the archaeological record to the municipal authorities. As a result, the practice of archaeology becomes connected with spatial planning and economic considerations, turning into some form of liability and "steering it away from [its] natural habitat: arts, heritage and culture in general" (Raemaekers 2014).

19. https://erc.europa.eu/projects-and-results/statistics

20. Lütticken (2014):http://svenlutticken.org/2014/ 11/12/holland-in-2014-a-culturednation/

21. http://www.futureofhumanities.eu/humanities-and -social-sciences-research-budgetreceives-significant- cuts-under-horizon-2020-framework/ (accessed Dec ember 2014).

22. https://www.change.org/p/college-van-bestuurred-de-geesteswetenschappen-aande-uva-save-thehumanities-at-theuva?utm_campaign=friend_inviter chat\&utm_medium $=$ facebook\&utm_source $=$ share _petition\&utm_term=permissions_dialog false\&share_id $=$ MOgXHBdWuB

23. http://www.globalheritage.nl/research

24. http://www.simplyamsterdam.nl/Tropenmuseum. htm

25. https://oxfordasiantextilegroup.wordpress.com /2013/06/25/tropenmuseumamsterdam-saved-fromclosure/

26. In article 16, paragraph 2 of the Greek Constitution (1982), it is stated that "Education comprises the main mission of the state...and has as the aim the moral, intellectual, professional and physical development of the Greeks...and their formation into free and responsible citizens."

27. Private tertiary education exists, usually in the form of branches of USA and EU universities, as well as Greek colleges. Degrees from these are not recognized by the Greek state as equivalent to public Greek universities, thus the deriving of "professional rights" is problematic, meaning exclusion from the (Greek) labor market.

28. Christine Lagarde, as Managing Director to the International Monetary Fund, publicly commented: "little kids from a school in a little village in Niger [...] need even more help than the people in Athens" because "all these people in Greece [...] are trying to escape tax" (The Guardian...). While the alleged tax evasion of an entire nation is fictitious, Lagarde's tax exemption on a six-digit annual salary, is a fact. "It's payback time: don't expect sympathy - Lagarde to Greeks," Guardian 25/5/2012, http://www.theguardian.com/ world/2012/may/25/payback-time-lagarde-greeks

29. http://www.enet.gr/?i=news.el.ellada\&id $=445156$

30. "In the ideology of our discipline the archaeologist exists to serve a higher goal, the search for knowledge, but archaeologists must also serve the archaeological record. This ideology includes a strong notion of self-sacrifice, that the archaeologist should sacrifice economic gain and even well-being to achieve knowledge and to protect the archaeological record." (McGuire and Walker's 1999, 164). The authors' "guild model" analogy worked, until now, for Europe too.

31. Bernbeck (2008) terms "structural violence" the practice of archaeology within academia that sees large asymmetries between the Middle East and other "peripheral areas" of the modern world and hot spots of "knowledge production" through modern capitalism. 
32. For example, in a recent announcement of 25 postdoctoral positions at the University of Liège, at the BeIPD-COFUND program, "The applicant must have obtained his/ her doctoral degree after 1 October 2010 or be in a position to obtain his/ her doctoral degree before 16 March 2016," thereby excluding people who gained their doctorates more than 5 years ago. A five year period is hardly a duration in which a researcher in Europe would be expected to secure a senior position that would render such a post-doctoral position attractive only to the least qualified of the "older PhD" holders, presumably the reasoning behind it.
33. Dr Sergis, affiliate of the Academy of Athens, an astrophysicist, collaborates with NASA, while living in Greece, computing the measurements required for the development of the space robot Cassini, which has been placed into an orbit around Saturn.

\section{References}

Bal, E., Grassiani, E. and K. Kirk. 2014. Neoliberal individualism in Dutch universities: teaching and learning anthropology in an insecure environment. Learning and Teaching 7 (3): 46-72.

Bartl, M. 2015. The way we do Europe: Subsidiarity and the substantive democratic deficit. European Law Journal 21: 23-43.

Bernbeck, R. 2008. Structural violence in archaeology. Archaeologies. Journal of the World Archaeological Congress 4(3): 390-413.

Bloommaert, J. 2016. Rationalizing the unreasonable: There are no good academics in EU. Urban Language \& Literacies . 186: 1-4.

Burrows, R. 2012. Living with the H-Index? Metric assemblages in the contemporary academy. The Sociological Review 60 (2): $355-356$.

Capano, G. and Piattoni, S. 2011. From Bologna to Lisbon: the political uses of the Lisbon 'script' in European higher education policy. Journal of European Public Policy 18(4): 584-606.

Davies, G. 2006. Subsidiarity: The wrong idea, in the wrong place, at the wrong time. Common Market Law Review 67-68.

Douzinas, C. 2013. Philosophy and Resistance in the Crisis: Greece and the Future of Europe. Cambridge: Polity Press.

Engelen, E., R. Fernandez and R. Hendrikse. 2014. How finance penetrates its other: A cautionary tale on the financialization of a Dutch University. Antipode 46(4): 1072-1091.

Fargues, P. 2014. Europe must take its share of share of the Syrian refugee burden, but how? Migration Policy Centre Research Report 2014/02. Florence: European University of Florence.

Fargues, P. and C. Fandrich 2012. The European response to the Syrian refugee crisis: what next? Migration Policy Centre Research Report 2012/14. Florence: European University of Florence.

Gerasimou, G. 2005. Price substitutes: the case of entrance to Greek universities. Applied Economic Letters 12: 723-727.
Gourgouris, S. 1996. Dream Nation: Enlightenment, Colonization, and the Institution of Modern Greece. Stanford: Stanford University Press.

Gruber, T. 2014. Academic sell-out: how an obsession with metrics and rankings is damaging academia. Journal of Marketing for Higher Education 24(2): 165-177

Halffman, W. and H. Radder. 2015. The Academic Manifesto: From an occupied to a Public University. Minerva. DOI: 10.1007/s11024-015-9270-9.

Halffman, H. 2014. No Merit in Precariat. Presentatie VAWO, 2014.

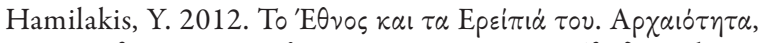

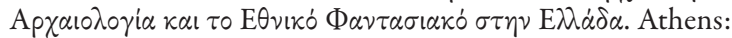
Ekdoseis toy Eikostoy Protou. Originally published: The Nation and its Ruins: Antiquity, Archaeology and National Imagination in Greece (Classical Presences), 2007. Oxford: Oxford University Press.

Hamilakis, Y. 2013 Double Colonization: The story of the excavations of the Athenian Agora (1924-1931). Hesperia 82: 153-177. Hamilakis, Y. and E. Yalouri 1996 Antiquities as symbolic capital in modern Greek society. Antiquity 70: 117-129.

Hamilakis, Y. and E. Yalouri 1999. Sacralising the past. Cults of archaeology in modern Greece. Archaeological Dialogues 1999(2): 115-135.

Hetel, L., T-E Møller and J. Stamm 2015. Integration of social sciences and humanities in horizon 2020: participants, budget and disciplines. Monitoring report on SSH-flagged projects funded in 2014 under the Societal Challenges and Industrial Leadership. Directorate-General for Research and Innovation 2015. Luxembourg: Publications Office of the European Union.

Holtorf, C. 2007. Can you hear me at the back? Archaeology, communication and society. European Journal of Archaeology 10(2-3): $149-165$ 
Karakasidou, A. N. 1994. Sacred scholars, profane advocates: intellectuals molding national consciousness in Greece. Identities $1(1): 35-61$.

Karanikolos, M., Mladovsky, P., Cylus, J., Thomson, S., Basu, S., Stuckler, D., Mackenbach, J. P.and McKee, M. 2013. Financial crisis, austerity, and health in Europe. Health in Europe 7.2013. The Lancet 381(9874): 1323-1331.

Karyotis, G. and R. Gerodimos 2013. The Politics of Extreme Austerity: Greece in the Eurozone Crisis. London: Palgrave Macmillan.

Killebrew, A. E. and Scham, S. 2015. Introduction. Forum. Investing the future of the past. Journal of Eastern Mediterranean Archaeology \& Heritage Studies 3(3): 234- 237

Kivinen, O. and J. Nurmi, 2003. Unifying Higher Education for different kinds of Europeans. Higher Education and Work: A comparison of ten countries. Comparative Education 39(1): 83-103.

Korres, G. M., Kourliouros, E., Gavalas, V., Kokkinou, A. 2012.

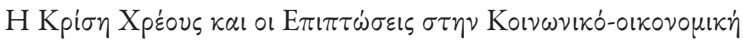

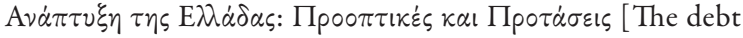
crisis and the impact in the socioeconomic development of Greece: perspectives and suggestions]. ERSA- GR, 10th Regular Scientific Conference, Thessaloniki 1-June 2012.

Kotsonas, A. 2015. Showcasing new Trojan wars: archaeological exhibitions and the politics of appropriation of ancient Troy. In Z. Theodoropoulou-Polychroniades and D. Evely (eds.), Aegis: Essays in Mediterranean Archaeology presented to Matti Egon by scholars of the Greek Archaeological Committee UK. Oxford: Archaeopress, 235-242.

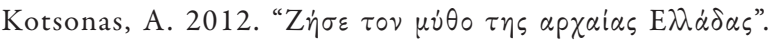

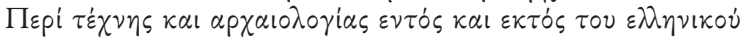
$\pi \alpha \nu \varepsilon \pi \iota \tau \tau \eta$ iov ["Live the myth of ancient Greece". On art and archaeology inside and outside the Greek university]. The Athens Review of Books (March): 44-47.

Kouvelakis, S. 2016. SYRIZA's rise and fall. New Left Review 97 (Interview 13): 43- 70

Lorenz, C. 2015. The Metrification of 'Quality' and the Fall of the Academic Profession. Oxford Magazine 355: 7-11

Lorenz, C. 2012. If you're so smart, why are you under surveillance? Universities, neoliberalism, and New Public Management. Critical Inquiry 38(3): 599-629.

Lütticken, S. 2014. Holland in 2014. A cultured nation. In Texts and Projects. http://svenlutticken.org/2014/11/12/ holland-in-2014-a-cultured-nation/

McGuire, R. and Walker, M. 1999. Class confrontations in archaeology. Historical Archaeology 33(1), Confronting Class, 159-183.

Mitsopoulos, M. and Pelagidis, T. 2009. Economic and social turbulence in Greece: the product markets are a no-brainer; the labor market is not. Journal of Intereconomics 44(4): 246-254.

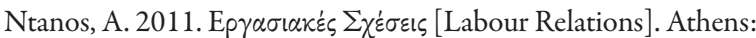
Syghroni Ekdotiki.

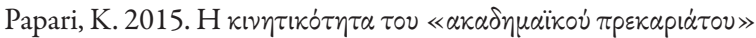
$\pi p \circ \varsigma \tau \eta \nu \pi \rho 0 \lambda \varepsilon \tau \alpha p ı \pi$ oin $\sigma \eta$. [The mobility of the 'academic precatariat' towards proletariasation] Hronos 30. http://chronosmag.eu/index.php/pp-e-p-p-plps.html

Papatheodorou, C. and Pavlopoulos, D. 2014. Income inequality in the EU: how do member states contribute? International Journal of Social Economics, 41 (6), 450- 466.

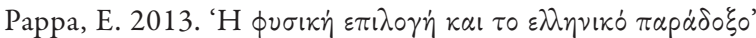

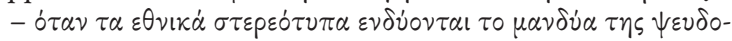

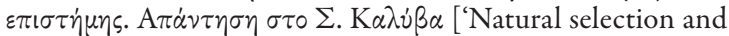
the Greek paradox' - when national stereotypes wear the mantle of pseudo-science. Response to S. Kalyvas]. Left.gr Daily Newsletter, published on 1.9.2013

Pavlopoulos, D. and Vassalos, G. 2015. Greece and the European neoliberal cage. New Left Project (March 2015). http://www. newleftproject.org/index.php/site/article_comments/greece and_the_euro pean_neoliberal_cage

Plantzos, D. 2014. Dead archaeologists, buried gods. Archaeology as an agent of modernity in Greece. In D. Tziovas (ed.), Reimagining the Past. Antiquity and Modern Greek Culture. Oxford: Oxford University Press, 147-164.

Plantzos, D. 2012. The glory that was not: Embodying the classical in contemporary Greece. Interactions: Studies in Communication \& Culture 3(2): 147-171.

Raemaekers, D. 2014. The pitfall of Dutch archaeology and re-establishing the societal relevance of archaeology in the Netherlands. Paper presented at the 21 st Archaeological Dialogues Symposium, Archaeology Today: Challenges, Approaches, Ethics, 22 April 2014, Amersfoort, Netherlands.

Saarinen, T. 2005. 'Quality' in the Bologna Process: from 'competitive edge' to quality assurance techniques. European Journal of Education 40(2): 189-204.

Saltini-Semerari, G. 2014. The postdoc application process: passing through the bottleneck. Paper presented at the 21st Archaeological Dialogues Symposium, Archaeology Today: Challenges, Approaches, Ethics, 22 April 2014, Amersfoort, Netherlands.

Scarre, C. and Scarre, G. 2006. The Ethics of Archaeology. Philosophical Perspectives on Archaeological Practice. Cambridge: Cambridge University Press

Scheerhout, D. 2004. Zonder publiek geen Malta. Archeologie en Publiek: 3: 1

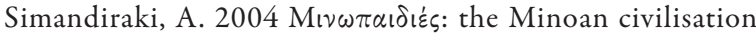
in Greek primary education. World Archaeology 36(2): 177-188.

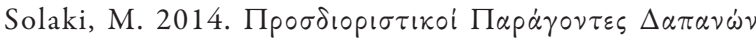

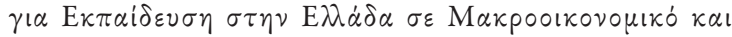
Miкpooıkovouıкó $\varepsilon \pi i \pi \varepsilon \delta \circ$ [Determinants of educational expenditures in Greece at macro-economic and micro-econimic level. PhD Thesis. Harokopeion University, Athens, Greece. 
Standing, G. 2014. The Precariat: The New Dangerous Class. London, Oxford; New York; New Delhi, Sydney: Bloomsbury Academic.

Tarler, D. 2015. An afterlife of sorts. Journal of Eastern Mediterranean Archaeology \& Heritage Studies 3(3): 270-276

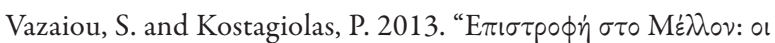

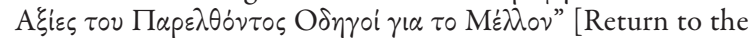
Future: the Values of the Past as Guides for the Future]. Paper presented at the 22nd Pan-Hellenic Conference on Academic Libraries. University and Information Centre, University of Patras.

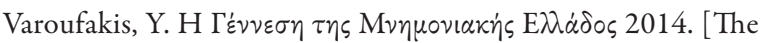
Birth of Memorandum Greece]. Athens: Gutenberg.

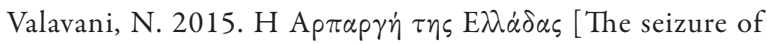
Greece]. Athens: Livanis.

van der Spek, B. 2009. De VU investeert te weinig in onderzoekers [The VU invests too little in researchers]. Ad Valvas 15 October 2009: 4. 